\title{
Youth in India: Situation and Needs 2006-2007-Executive summary
}

International Institute for Population Sciences (IIPS)

Population Council

Follow this and additional works at: https://knowledgecommons.popcouncil.org/departments_sbsr-pgy

Part of the Demography, Population, and Ecology Commons, Family, Life Course, and Society Commons, International Public Health Commons, Maternal and Child Health Commons, Medicine and Health Commons, and the Women's Health Commons How does access to this work benefit you? Let us know!

\section{Recommended Citation}

International Institute for Population Sciences (IIPS) and Population Council. 2010. "Youth in India: Situation and Needs 2006-2007-Executive summary." Mumbai: IIPS. 


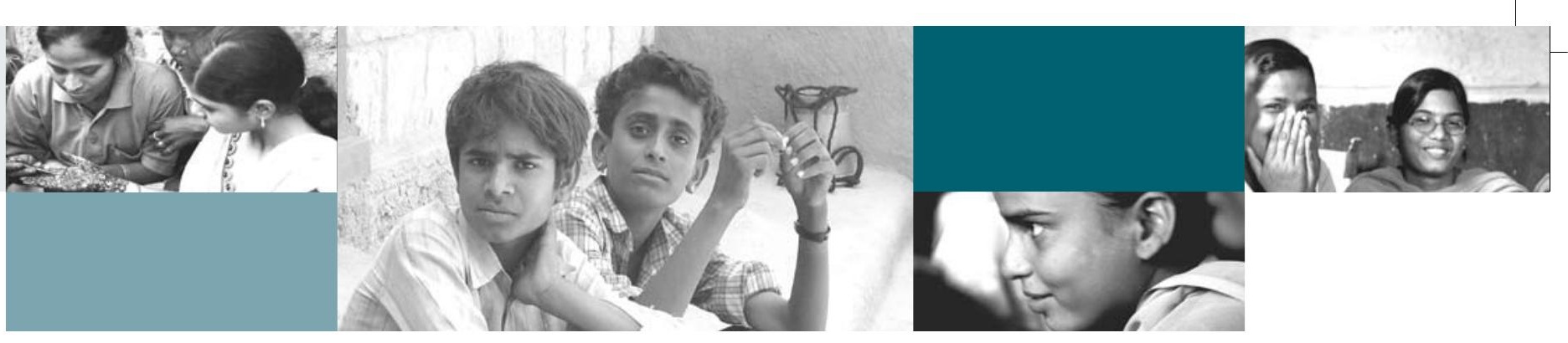

Voung people (aged 10-24) constituted almost 315 million and represented 31\% of the Indian population in 2001. Not only does this cohort represent India's future in the socio-economic and political realms, but its experiences will largely determine India's achievement of its goal of population stabilisation and the extent to which the nation will be able to harness its demographic dividend. While today's youth are healthier, more urbanised and better educated than earlier generations, social and economic vulnerabilities persist. In the course of the transition to adulthood, moreover, young people face significant risks related to sexual and reproductive health, and many lack the knowledge and power to make informed sexual and reproductive choices.

In recognition of the importance of investing in young people, several national policies and programmes formulated since 2000 , including the National Population Policy 2000, the National Youth Policy 2003, the Tenth and Eleventh Five-Year Plans, the National Adolescent Reproductive and Sexual Health Strategy and the National Rural Health Mission, have underscored a commitment to addressing the multiple needs of this group in India. Effective implementation of both policies and programmes, however, has been handicapped by the lack of evidence on young people's situation and needs. Currently available evidence is limited, at best, and comes largely from small-scale and unrepresentative studies.

The Youth in India: Situation and Needs study (referred to as the Youth Study), implemented by the International Institute for Population Sciences, Mumbai and the Population Council, New Delhi is the first-ever sub-nationally representative study conducted to fill these gaps in evidence. Its objectives were to identify key transitions experienced by youth, including those pertaining to education, work force participation, sexual activity, marriage, health and civic participation; provide state-level evidence on the magnitude and patterns of young people's sexual and reproductive practices in and outside of marriage as well as related knowledge, decision-making and attitudes; and, finally, identify key factors underlying young people's sexual and reproductive health knowledge, attitudes and life choices.

The Youth Study focused on married and unmarried young women and unmarried young men aged 15-24 and, because of the paucity of married young men in the younger ages, married men aged 15-29, in both rural and urban settings. The study was conducted in Andhra Pradesh, Bihar, Jharkhand, Maharashtra, Rajasthan and Tamil Nadu; these states were purposively selected to represent the different geographic and socio-cultural regions within the country. Indeed, these six states together represent $39 \%$ of the country's population. This report focuses on the consolidated findings from youth interviewed from all the six states. A more detailed description of findings from each state have been published elsewhere (IIPS and Population Council, 2008; 2009a; 2009b; 2009c; 2009d; 2010). 
The study comprised three phases, and included both a survey and qualitative data gathering exercises prior to and after the survey. The surveys were undertaken in a phased manner and took place between January 2006 and April 2008. In all, 58,728 young people were contacted, of which a total of 50,848 married and unmarried young women and men were successfully interviewed.

\section{Characteristics of the household population}

A total of 186,152 households were selected for interview. Among these, interviews were successfully completed in 174,037 sample households, and 838,731 individuals, who were usual residents in these households, were enumerated.

The age distribution of the six states was typical of a population in which fertility has been declining in the recent past. A little over one-fifth (22\%) of the population was aged o-9 years, and at the other end of the age spectrum, the population aged 6o+ years represented $9 \%$. Findings suggest, moreover, that the proportion of the population aged o-4years was similar to that observed in the 2001 census in these six states (10.0 and 10.7 respectively), and the median age of the population was slightly higher than that reported in the 2001 Census (24 years versus 22.6 years). With regard to the population of young people, the distribution suggests that at the time of the survey, $11.4 \%$ of the population was aged 10-14 years, $9.5 \%$ was aged 15-19 years and $8.6 \%$ was aged $20-24$ years. A total of $18.1 \%$ of the population was aged 15-24 years, about the same as that observed in the 2001 Census (18.3\%) Overall, the sex ratio of the de jure population was 992 females per 1,000 males, somewhat higher than that observed for these six states in the 2001 Census (943). A similar pattern was observed in both rural (1,005 compared to 955 in the 2001 census) and urban areas (956 and 915, respectively). The child sex ratio of the surveyed population was 920 females per 1,000 males aged o-6, similar to that reported in the 2001 Census (935).

The educational profile of the household population highlights low levels of educational attainment: over one-third (36\%) of the population aged 6 years and above had no formal education. Notably, as many as $47 \%$ of females compared to $26 \%$ of males, and as many as $43 \%$ of the rural population compared to $19 \%$ of the urban population, had never been to school. Reaffirming the low levels of educational attainment in the population covered by the study, findings also indicate that just $11 \%$ of the total population had received 12 or more years of education, including $14 \%$ and $7 \%$ of males and females, respectively.

Housing characteristics of the surveyed population underscore poor living conditions among the majority of the population covered. Overall, $28 \%$ of households lived in kachcha houses (constructed from mud, thatch or other low-quality materials), 34\% lived in semi-pucca houses (constructed using a mix of low- and high-quality materials) and $38 \%$ lived in pucca houses (constructed entirely from cement, masonry or other high-quality materials). Only $68 \%$ of households had electricity, including $94 \%$ of urban households and $58 \%$ of rural households. 
Little less than nine in ten households (88\%) reported that their main source of drinking water was piped water, or water obtained from a hand-pump or a covered well. Access to a toilet facility of any kind was reported by about one-third (36\%) of households. Finally, the main source of cooking fuel was coal, charcoal, wood, crop residue or dung cakes, reported by $72 \%$ of households; liquid petroleum gas (LPG) was used, in contrast, by just $23 \%$ of households. With regard to the availability of household amenities such as electricity, piped water and gas connections, findings suggest that the northern states, especially Bihar and Jharkhand were comparatively worse off than Maharashtra and the southern states.

The distribution of households by wealth quintiles shows a stark rural-urban divide: over two-fifths (45\%) of urban households were in the wealthiest (fifth) quintile; in contrast, only one-tenth of rural households were in this quintile. Likewise, one-quarter of rural households were in the poorest (first) quintile of the index compared to only $4 \%$ of urban households. Findings also highlight that poverty levels were higher in Bihar and Jharkhand than in any of the other states, with considerably more households in these states (39-44\%) falling into the poorest (first) quintile compared to those in the other four states (8-18\%).

\section{Situation of youth}

As mentioned earlier, a total of 50,848 youth were interviewed. Age profiles suggest that a somewhat larger proportion of young men and women were concentrated in the 15-19 than in the $20-24$ age group (52-53\% compared to 47-48\%). Moreover, the unmarried were clearly younger than the married; while $78 \%$ of unmarried young women were aged $15-19$, only $31 \%$ of married women fell into these ages. The distribution of youth by religion shows that $83-85 \%$ of youth were Hindu, $10 \%$ were Muslim and $5-7 \%$ belonged to other religions. Caste-wise distributions were generally similar among young men and women, with about half (49-50\%) falling into other backward castes, $20-21 \%$ into scheduled castes, $7-9 \%$ into scheduled tribes and $21 \%$ into general castes. More than four in five young men and women (84-85\%) reported that both parents were surviving. For those with just one parent surviving, this parent was more likely to be the mother (11\%) than the father (3-4\%). Finally, $1-2 \%$ reported that neither parent was alive.

\section{Education}

While youth in the country were better educated than the general population, schooling was far from universal among them. Almost one in ten young men and one in four young women had never attended school. Findings show, moreover, that young women in rural areas and married young women were particularly disadvantaged; one-third of rural young women and almost two-fifths of married young women had never been to school. State-wise differences were also apparent: $10-16 \%$ of young men and $38-51 \%$ of young women from the northern states had never been to school, compared to $2-8 \%$ and $5-21 \%$, respectively, in Maharashtra and the southern states. 
Percentage of youth who had never been to school by state

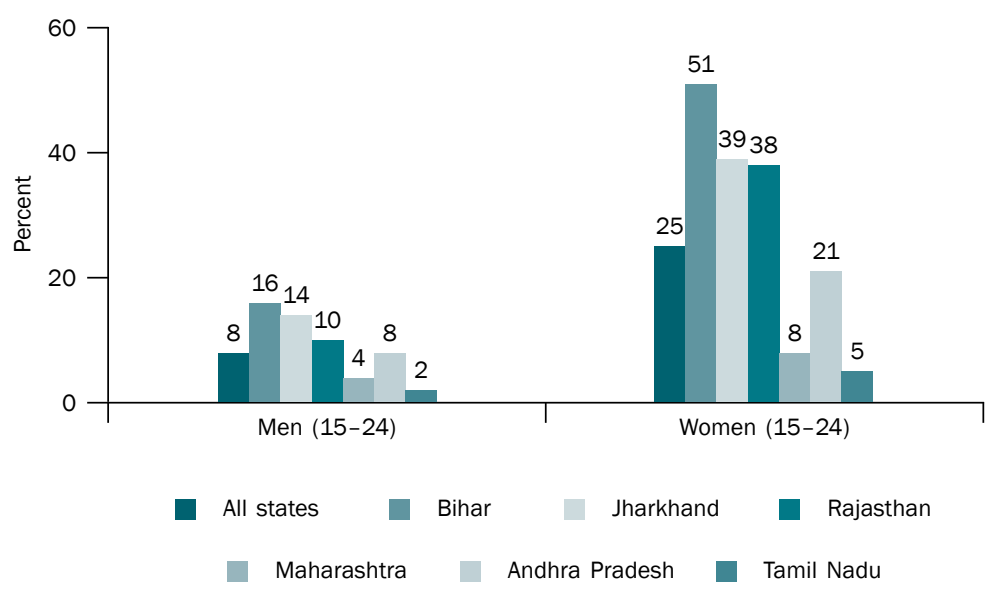

Attainment of educational milestones also varied. In total, just two in fiveyoung men and one in three young women had completed high school. The rates were particularly low among several sub-groups of youth-young women, married youth, rural youth, those belonging to poor households, Muslim youth and those belonging to scheduled castes and tribes. Similarly, far smaller

proportions of youth in the northern states than those in Maharashtra and the southern states had completed 10 or more years of education.

Among those who had ever enrolled in school, substantial declines in school completion rates took place earlier among young women than men, the married than the unmarried, and the rural compared to the urban. State-wise differences were less consistent. Major declines occurred earlier in the northern states and Andhra Pradesh than in Maharashtra and Tamil Nadu. Moreover, in all groups and all states, major declines occurred just prior to high school completion (between Classes 9 and 10) as well as following the completion of such milestones as a secondary, higher secondary and college education.

The leading reason for never attending school among young men and women was economic (for example, the respondent was required for work on the family farm/business or for outside wage earning work, or the family could not afford school-related expenses), reported by about three in

Cumulative percentage of youth who had completed each year of education (Classes 1 to 17), combined

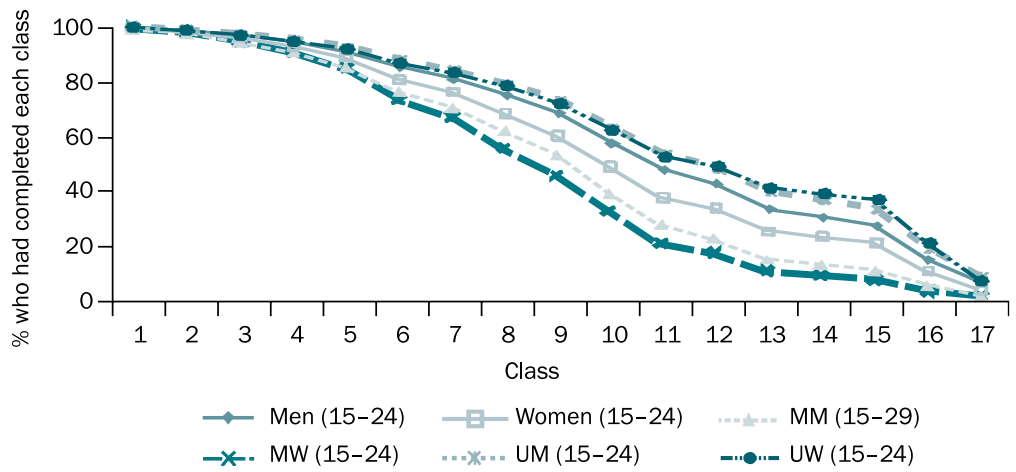

$\mathrm{MM}=$ Married men; MW=Married women; $\mathrm{UM}=$ Unmarried men; UW=Unmarried women five young men and women. More than half of young women, moreover, reported reasons related to housework (the respondent was required for care of siblings or housework). Attitude- or perception-related reasons (for example, education was unnecessary or the respondent was not interested in schooling) were other important reasons for never going 
to school, reported by one-third of young men and women. Finally, school-related reasons (school located too far away, poor school quality and so on) were important, particularly among young women.

Among those who had ever been to school, gender differences in reasons for discontinuation became more apparent. Leading reasons for discontinuation among young men, irrespective of the level at which schooling had been discontinued, continued to be economic and attitude- and perception-related, and at higher levels, school-related as well. For young women, while percentages differed, leading reasons were economic, attitude- or perception-related, housework responsibilities and school-related. Among young women, moreover, reasons relating to transitions to adult roles, overwhelmingly marriage became increasingly important among those who had discontinued their education at the secondary or higher secondary level. Of note, particularly, is that one in seven and one in four young women who had discontinued their education in Classes 7-9 and 10-11, respectively, reported reasons related to transitions to adult roles, notably marriage.

For the most part, youth attended co-educational and government schools and colleges. A gender divide was, however, observed in the type of educational facility they attended. While young men, by and large, attended co-educational facilities at all levels of education, percentages of young women attending a co-educational facility declined with level of schooling attained. Moreover, percentages of young men and women attending private educational facilities increased with level of education.
Cumulative percentage of youth who had completed each year of education (Classes 1 to 17 ), urban

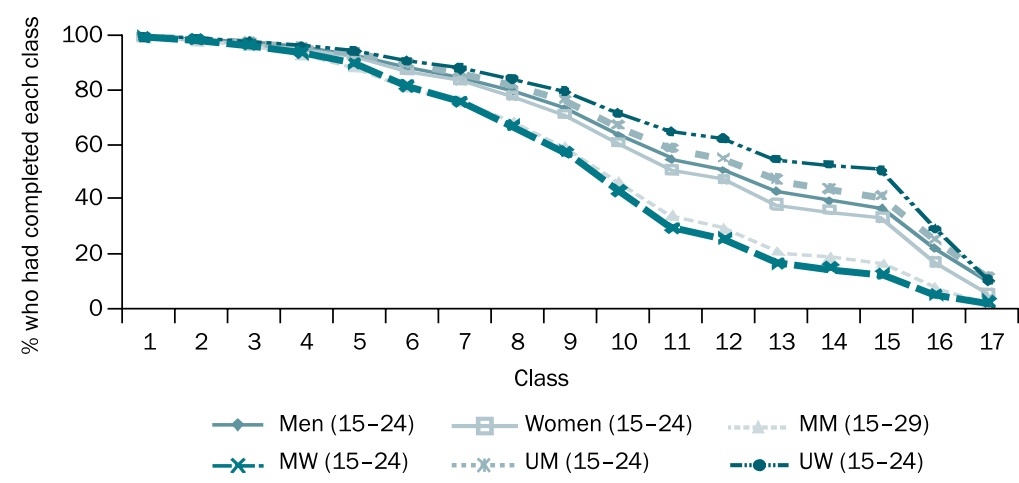

$\mathrm{MM}=$ Married men; $\mathrm{MW}=$ Married women; UM=Unmarried men; UW=Unmarried women

\section{Cumulative percentage of youth who had completed each year of education (Classes 1 to 17), rural}

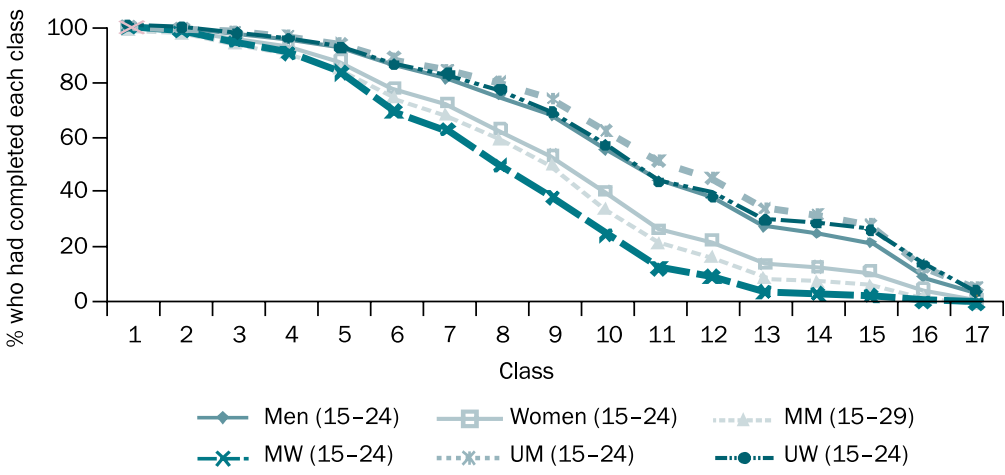

MM=Married men; MW=Married women; UM=Unmarried men; UW=Unmarried women 
Percentage of youth who had discontinued schooling by class when discontinued and reasons for discontinuation

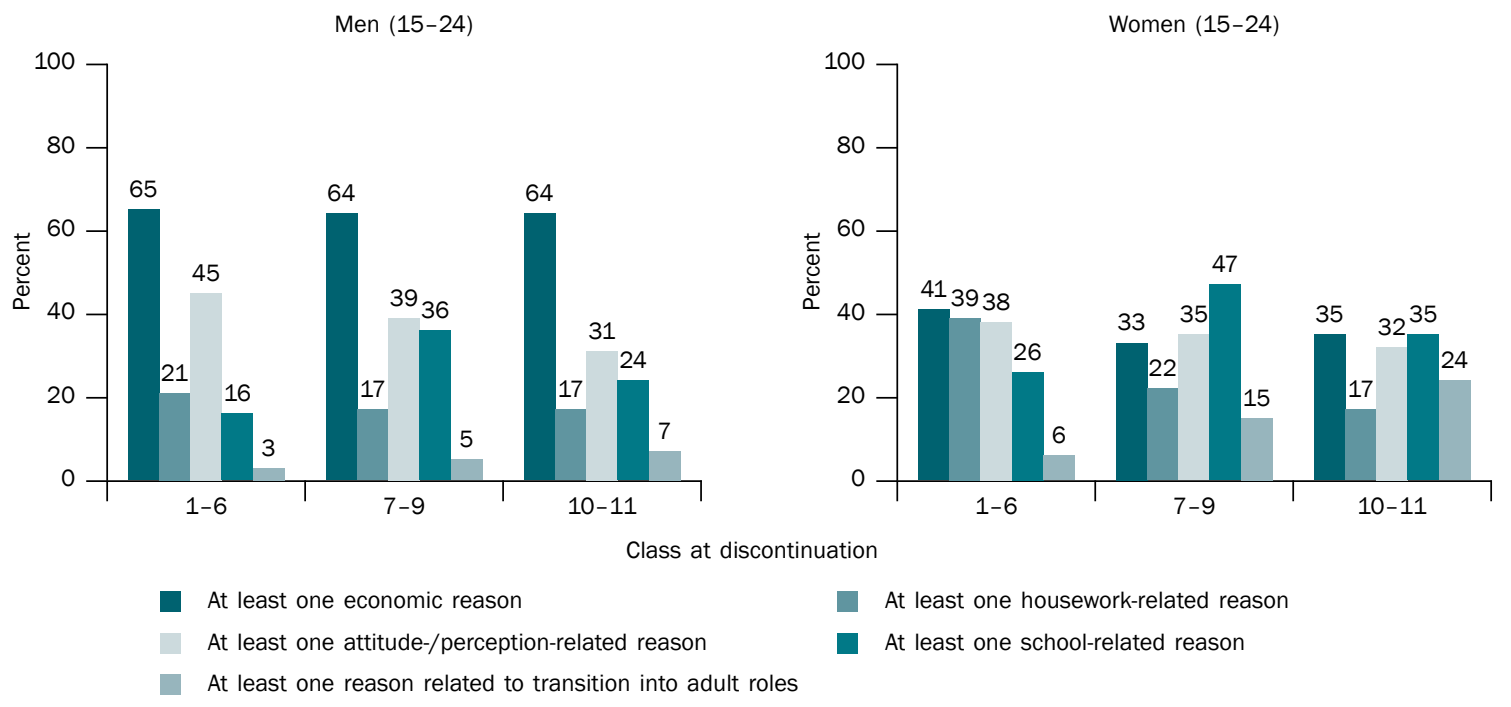

As far as availability of such amenities as drinking water, playgrounds, toilets and libraries was concerned, almost all youth had access to drinking water, and considerable majorities to playgrounds. Toilets and library facilities were less likely to be reported by youth, irrespective of their schooling status at the time of the interview. By and large, differences were observed in the availability of amenities at educational facilities attended by youth who were still in school and those who had discontinued their education at various levels. Indeed, youth who were still studying were somewhat more likely to report the availability of all four amenities-water, toilets, playgrounds and libraries - than were those who had discontinued their education: for example, among those at higher secondary or college level at the time of the interview, $70-77 \%$ reported access to all four amenities, compared with $62-65 \%$ among those who had discontinued their education at these levels.

Schooling experiences were relatively similar among young men and women but differed somewhat among those who had discontinued schooling and those who were studying at the time of the interview. While differences in regular attendance and perceptions about academic load were less consistent, youth who were continuing their education were considerably more likely to report private tuition, and to have passed the last examination for which they had appeared. It would appear that academic failure was an important factor precipitating school discontinuation.

\section{Work}

Work profiles suggest that over two-thirds of young men and one-half of young women had at some time engaged in paid or unpaid work. Indeed, almost all married young men and almost two-thirds of unmarried young men had done so, compared with three-fifths and two-fifths of 
married and unmarried young women, respectively. Likewise, more youth in rural than urban areas had ever worked: differences were mild among men (74\% versus $62 \%$ ) and considerable among young women (58\% versus 30\%). Young men and women were far less likely to have engaged in unpaid than in paid work. Economic activity was often initiated at an early age: over one in four young men and women reported initiating work in childhood or early adolescence (by age 15).

Data on work participation in the 12 months prior to interview indicate that the majority of young men (61\% of unmarried and $97 \%$ of married) and a substantial proportion of young women (37\% and $43 \%$, respectively) had engaged in paid or unpaid work at some point in the 12 months preceding the interview. The majority of young men and women who had worked in the year prior to the interview had done so for the major part (at least six months) of the year.

Findings also suggest substantial levels of unemployment among youth: $14 \%$ among young men and $16 \%$ among young women. Unemployment was particularly high among the educated-young men and women who had completed Class 12 reported considerably higher rates of unemployment than those who had completed fewer years of schooling.

Percentage of youth who had ever attended a vocational training programme and percentage who were interested in participating in such programmes

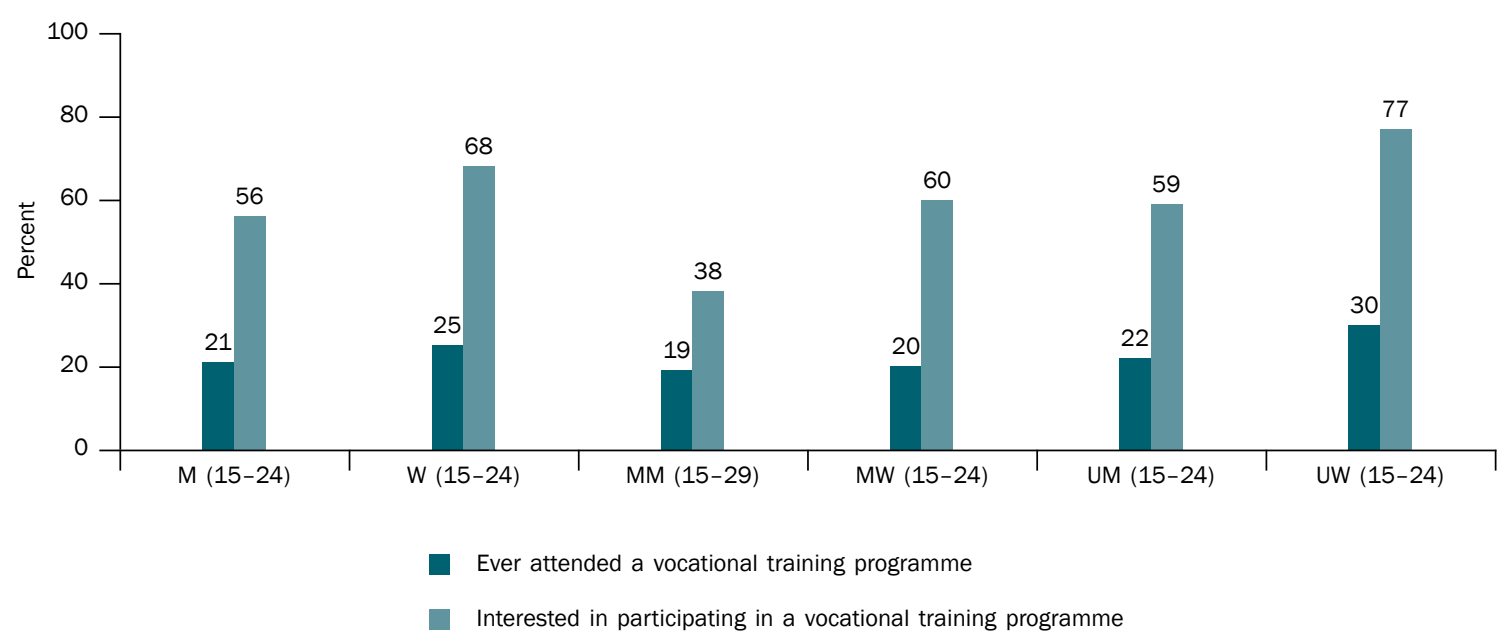

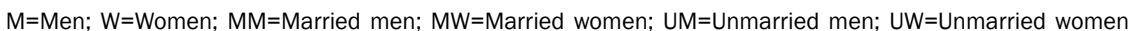

Percentage of youth who had engaged in

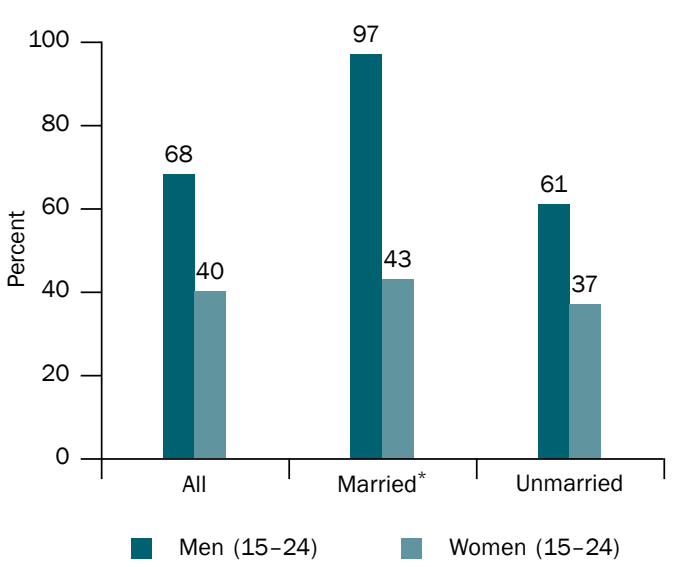

Note: *Married men (15-29). 
Youth were clearly interested in acquiring skills that would enable employment generation; over half of young men and two-thirds of young women reported interest in vocational skills training. However, far fewer-just $21 \%$ of young men and $25 \%$ of young women-had attended at least one vocational training programme.

Finally, while no clear regional patterns were evident in terms of young people's work profiles, findings suggest a regional divide with regard to young people's participation in vocational training programmes. Youth in Maharashtra and the southern states were more likely than their northern counterparts to have ever attended vocational training programmes. While this regional pattern was not as consistently observed with regard to young people's interest in attending vocational training programmes in general, those from the northern states were consistently less likely than their counterparts from Maharashtra and the southern states to express a preference for training in new technologies, namely, computer skills.

\section{Media exposure}

Findings suggest that large proportions of all youth were exposed to the media, typically television ( $89 \%$ of all young men and $76 \%$ of all young women), and, among youth with five or more years of education, newspapers, magazines or books (93\% of young men and $78 \%$ of young women). Exposure to the internet, among those with five or more years of education, was reported by considerably fewer youth ( $15 \%$ of young men and $9 \%$ of young women). Gender differences were apparent, with young men typically more likely to be exposed to each medium than young women. State-level differences were narrow with regard to exposure to the print media, but wider in the case of the remaining two media; youth in Maharashtra and the southern states were, by and large, more likely than their counterparts in the northern states to report exposure to television and the internet. For example of those who had completed five or more years of education, $14-26 \%$ of young men and $9-14 \%$ of young women in Maharashtra and the southern states, compared to $6-11 \%$ and $3-6 \%$, respectively, in the northern states, had accessed the internet. Indeed, internet exposure was most likely to be reported by young men in Andhra Pradesh and Tamil Nadu than by those in the other states $(22-26 \%$ Percentage of youth who had accessed the internet by state versus $6-14 \%$ with five or more years of education in the remaining states); among young women, differences were narrower, but young women in Tamil Nadu (14\%) were considerably more likely than those in the other states (3-9\%) to report internet exposure.

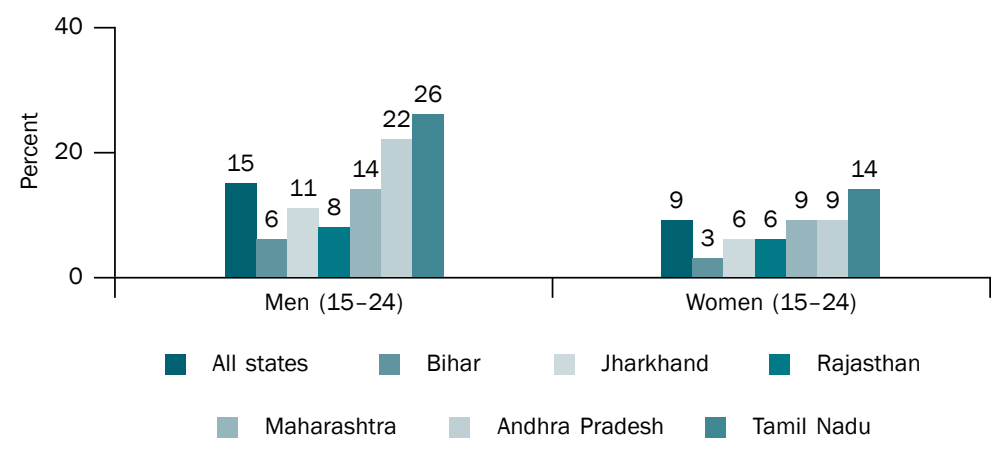


Findings also suggest that about one in three young men (35\%) and hardly any (3\%) young women watched pornographic films; $23 \%$ of young men and $5 \%$ of young women accessed pornographic books and magazines and $37 \%$ of young men and $5 \%$ of young women who had been exposed to the internet had accessed pornographic materials on the internet. State-level differences were inconsistent but highlight that young men in Maharashtra and the southern states were more likely than those in the northern states to report exposure to pornographic materials. Notably, young men in Andhra Pradesh were consistently more likely than those in the other states to access pornographic materials on films, in books and magazines, and on the internet.

Finally, between half and three-fifths of young men and women (54-62\%) acknowledged the influence that media have on youth behaviours, in terms of influencing the way youth dress or the extent to which they exhibit aggressive behaviours.

\section{Socialisation experiences and communication with parents}

Youth Study findings confirm that puberty occurs in the early teens among both young men and women. The mean age at menarche was 13.5 years, and young men typically reported voice change and the appearance of pubic hair at age 15 .

Findings underscore, in general, the gendered socialisation of youth. For example, responses of both young men and women indicate that unequal gender norms regarding freedom of movement prevailed in most study households, with more than two-thirds of young men acknowledging that they had more freedom to go out than their sisters or female cousins did, and more than half of young women agreeing that they had less freedom to go out than their brothers or male cousins. At the same time, more than half of young men and women reported that young men in their family were expected to do less housework than were young women. Findings also suggest that parents controlled both young men's and women's social interactions, particularly those involving members of the opposite-sex: For example, $69 \%$ of young men and $82-84 \%$ of young women expected parental disapproval if they brought an opposite-sex friend home.

Findings regarding communication with parents on issues relevant to youth-such as school performance, romantic relationships, growing up matters and reproductive processes-reiterate those from other studies, showing that such communication is far from universal. Indeed, sensitive topics-such as romantic relationships and reproductive processes-were rarely discussed with either parent, and growing up matters were discussed only by young women with their mother.

That parent-child communication was restricted was also evident from responses to questions probing the most likely confidante on a range of topics from taking a job to boy-girl relationships. While a parent was mentioned as the leading confidante on the subject of taking a job, a parent was rarely cited as a leading confidante on the more sensitive matter of boy-girl relationships. 
Percentage of youth reporting gendered socialisation experiences relative to an opposite-sex sibling/cousin

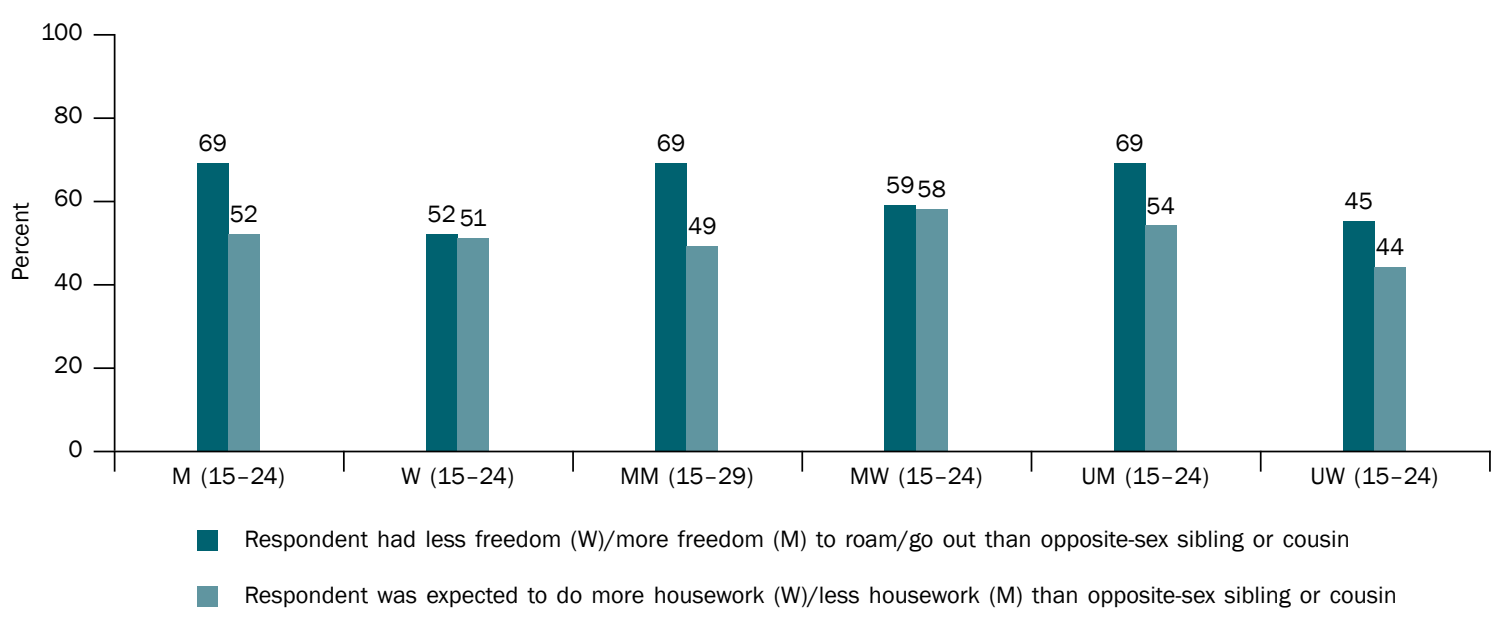

$\mathrm{M}=$ Men; $\mathrm{W}=$ Women; $\mathrm{MM}=$ Married men; $\mathrm{MW}=$ Married women; $\mathrm{UM}=$ Unmarried men; $\mathrm{UW}=$ Unmarried women

Note: For married respondents, questions referred to the period prior to marriage.

Moreover, while young women identified their mother as the most likely confidante on menstrual problems, young men rarely identified a parent as a leading confidante on matters relating to nocturnal emission or swapnadosh.

Young people's family lives were marked by violence, both witnessed and experienced. As many as one-quarter of young men and women had observed their father beating their mother. Many respondents reported experiencing a beating by a parent during adolescence; gender differences were marked, with almost half of young men and one-fifth of young women reporting such experiences.

In contrast, growing up was associated with close peer networks. Almost all youth reported having some same-sex friends. Young men typically reported a somewhat larger network of friends than did young women. Opposite-sex peer networks were less common but nonetheless reported by $27 \%$ of young men and $16 \%$ of young women. Indeed, findings suggest that youth derived an important measure of support from their peer networks on personal matters: friends were by far the leading confidante on boy-girl relationships for both young men and women, and on nocturnal emission for young men.

Our findings also suggest the familiar north-south divide with regard to the growing up experiences of young men and women, although these differences were not consistently observed. Of note were findings that fewer young men from Maharashtra and the southern states than from the northern states perceived disapproval from their parents if they brought opposite-sex friends home. And more young women from Maharashtra and the southern states than those from the northern states cited a parent or family member as their leading confidante on matters related 
to taking a job or menstrual problems. Even so, evidence of domestic violence did not follow this pattern: youth in the southern states were most likely to have witnessed their father beating their mother and to have been beaten by a parent.

\section{Peer networks and interaction}

In contrast, growing up was associated with close peer networks. Almost all youth reported having some same-sex friends. Young men typically reported a somewhat larger network of friends than did young women. Opposite-sex peer networks were less common but nonetheless reported by $27 \%$ of young men and $16 \%$ of young women. Indeed, findings suggest that youth derived an important measure of support from their peer networks on personal matters: friends were by far the leading confidante on boy-girl relationships for both young men and women, and on nocturnal emission for young men.

State-wise differences were apparent with regard to peer relations. Youth in the northern states were less likely than those in Maharashtra and the southern states to report five or more same-sex friends or an opposite-sex friend. Moreover, young men in Maharashtra and the southern states were more likely than those from the northern states to cite a friend as their leading confidante on such matters as taking a job, anxiety about nocturnal emission and boy-girl relationships; so too, young women in Maharashtra and the southern states were more likely than their northern counterparts to cite a friend as a leading confidante on boy-girl relationships.

\section{Agency and gender role attitudes}

Findings clearly highlight young women's limited agency. For example, just one in four young women (27\%) reported independent decision-making on all three issues explored in the survey, namely, decisions on choice of friends, spending money and purchase of clothes for oneself. Likewise, freedom of movement even within the village or neighbourhood was not universal among young women; only three-quarters of young women (73\%) had the freedom to visit locations within their own village or neighbourhood unescorted. Moreover, just one-quarter of young women reported freedom to visit at least one place outside the village or neighbourhood unescorted, and $15 \%$ could visit a health facility unescorted. Access to and control over financial resources tended to be limited among young women;

\section{Percentage of youth who independently made decisions on choice of friends, spending money and buying clothes for themselves}

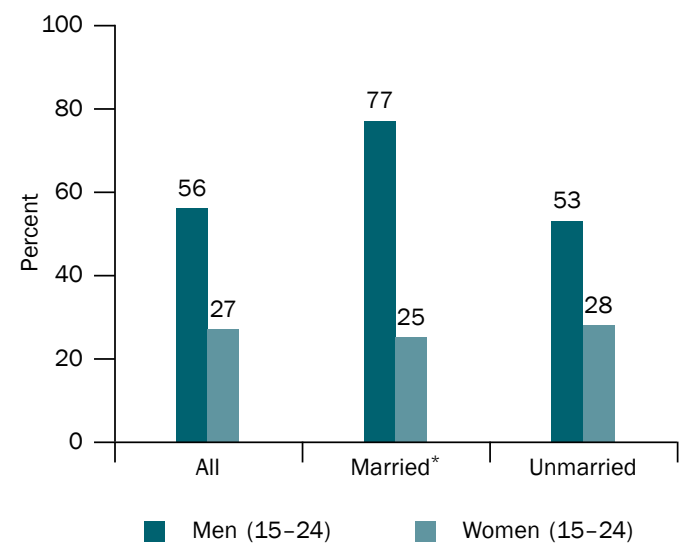

Note: *Married men (15-29). 
Percentage of youth allowed to visit selected places unescorted

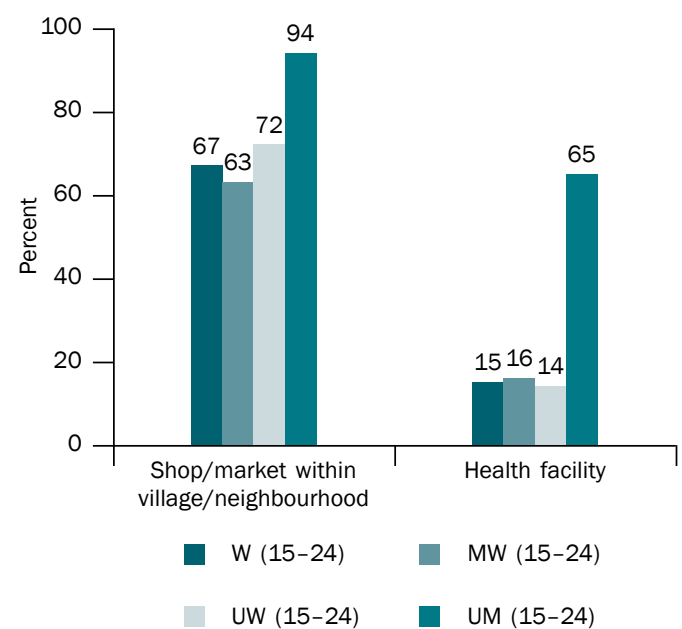

$\mathrm{W}=$ Women; $\mathrm{MW}=$ Married women; $\mathrm{UM}=$ Unmarried men; UW=Unmarried women

Note: Questions regarding freedom of movement were not asked of married men, as their mobility is generally unrestricted. fewer than two in five reported some savings and one in 10 owned a bank or post office savings account. Of those who owned an account, just $54 \%$ operated it themselves. While in each state, women's agency was limited, a clear state-wise pattern was not discernible. For example, young women from Maharashtra displayed considerably higher levels of decision-making than did those from the other states. However, young women from the southern states were more likely than those from the other states to report freedom to visit places within the village or neighbourhood, and those from Maharashtra and the southern states were more likely than those from the other states to report mobility outside the village or neighbourhood. Although young women in the southern states were about as likely as those from the other states to own an account, they were considerably more likely to operate the account independently.

Also notable from the findings is the striking gender divide in all the dimensions of young people's agency explored in the survey. Young women were far more disadvantaged than young men, and this was apparent in each state. For example, even the least

Percentage of youth who reported having any savings, owning an account in a bank or post office and operating the account themselves

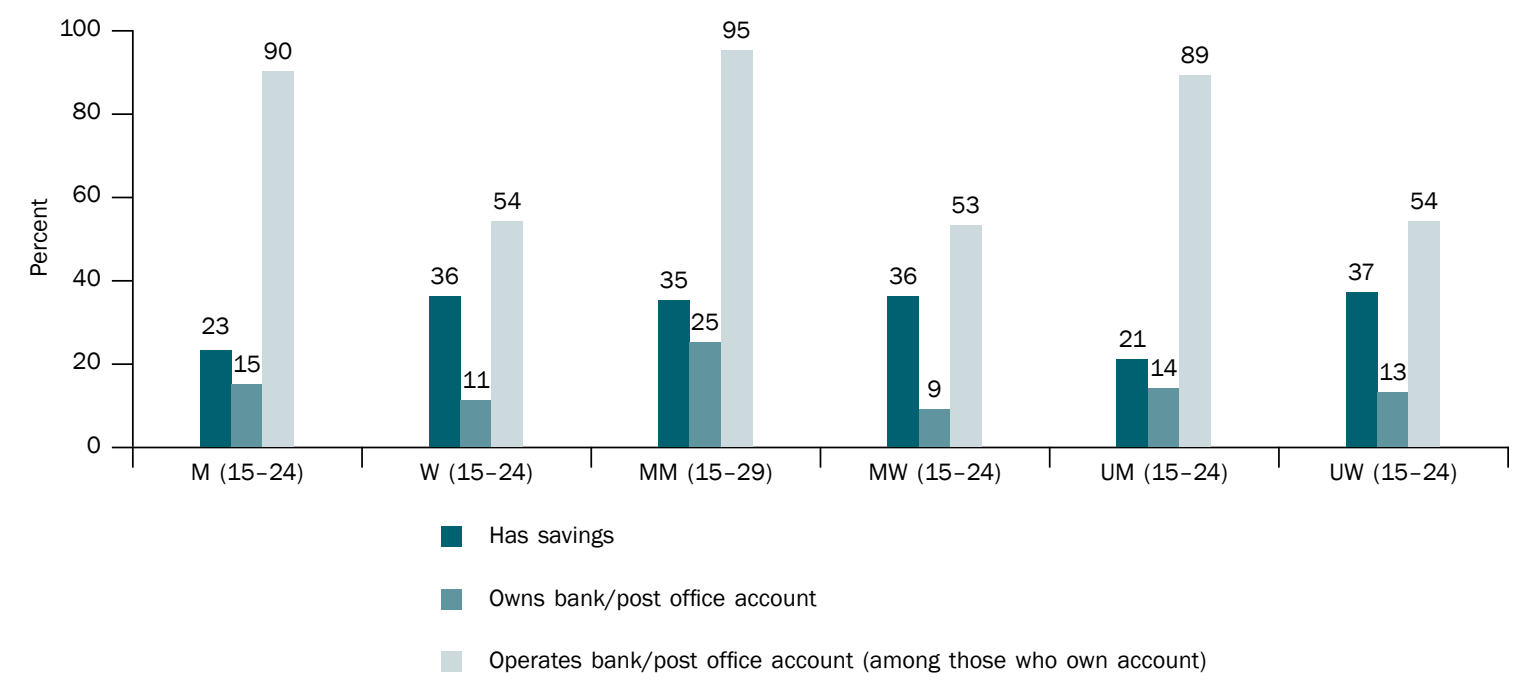

$\mathrm{M}=$ Men; $\mathrm{W}=$ Women; $\mathrm{MM}=$ Married men; $\mathrm{MW}=$ Married women; $\mathrm{UM}=$ Unmarried men; UW=Unmarried women 
Percentage of youth who believed wife beating is justified in selected situations

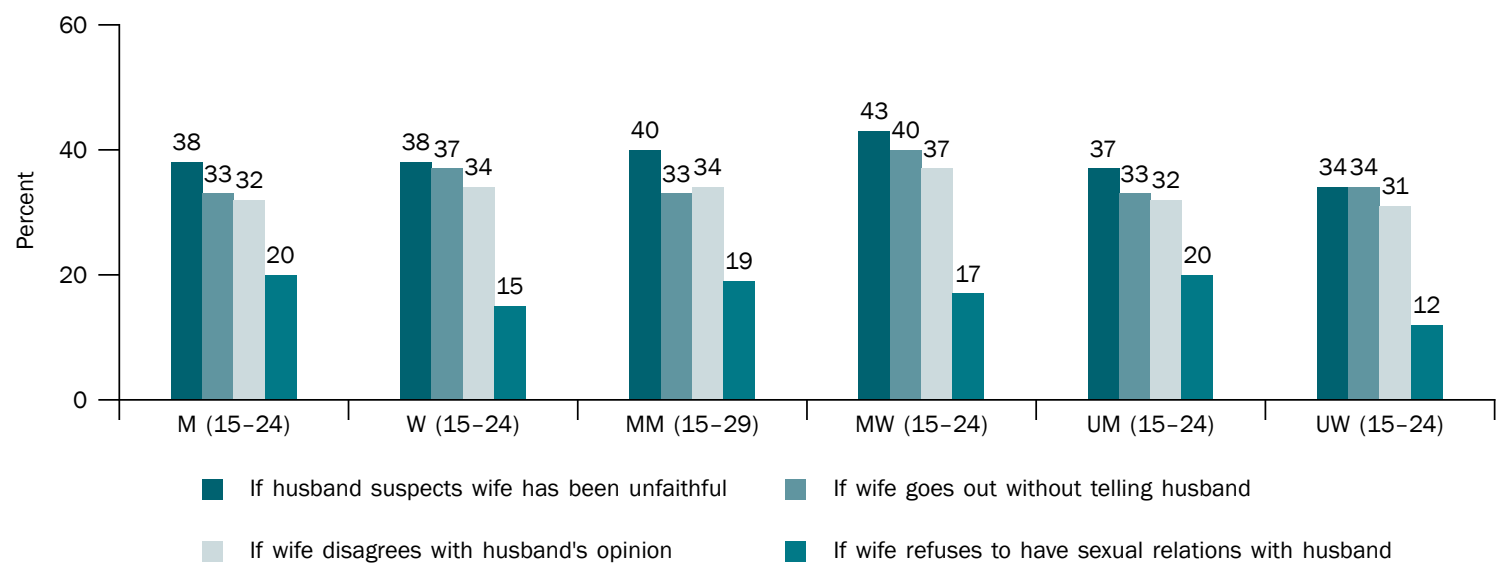

M=Men; W=Women; MM=Married men; MW=Married women; UM=Unmarried men; UW=Unmarried women

educated young men and young men belonging to the poorest (first) wealth quintile were more likely than the most educated women and those in the wealthiest (fifth) quintile to report independent decision-making on all three issues explored in the survey. Likewise, although young women were more likely than young men to have money saved (36\% and $23 \%$, respectively), they were slightly less likely than young men to own a bank or post office savings account (11\% and 15\%, respectively). Moreover, young women were much less likely than their male counterparts to operate these accounts themselves (54\% versus 90\% of those who had an account).

While young men were not as disadvantaged as young women, findings indicate that many young men were also not able to exercise agency in their everyday lives, and this was evident in each state as well. For example, only $56 \%$ of young men reported independent decision-making on all three issues explored in the survey. Unmarried young men had considerable freedom of movement, yet more than one-third were not permitted to visit a place of entertainment or attend a programme conducted outside their village or neighbourhood, or visit a health facility unescorted.

Percentage of youth who believed wife beating is justified in at least one situation by state

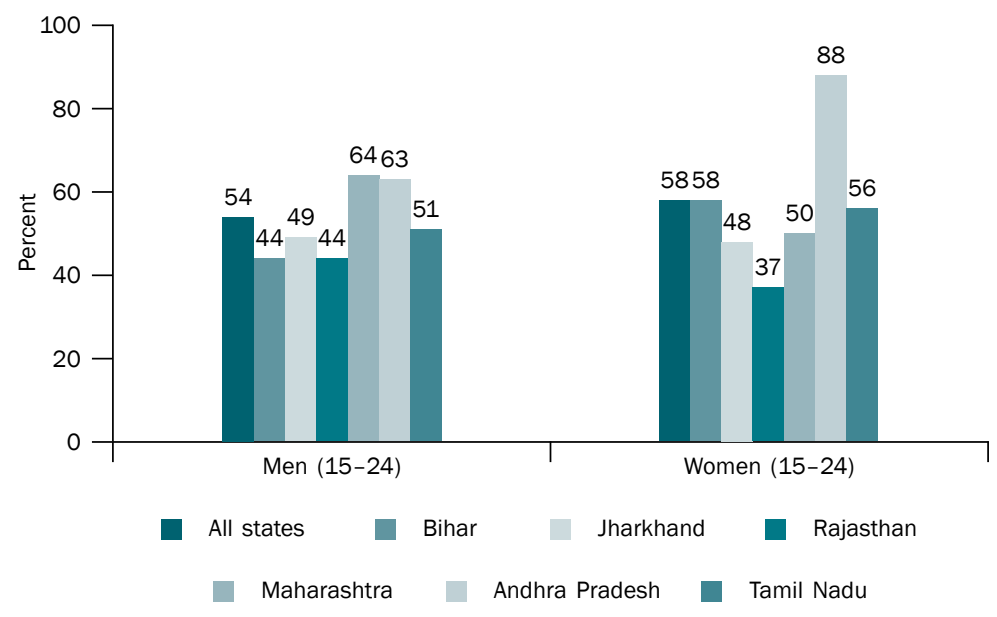


More than half of young men and women ( $54 \%$ and $58 \%$, respectively) justified wife beating in at least one situation. At the same time, relatively large proportions of youth espoused egalitarian gender role attitudes on other issues explored. It is notable that young men were consistently more likely than young women to report unequal gender role attitudes on these issues. State-wise differences suggest that youth in Maharashtra and the southern states were more likely than their counterparts in the northern states to express egalitarian gender role attitudes. While a similar regional pattern was observed with regard to attitudes to wife beating among young men, regional patterns in attitudes towards wife beating were difficult to discern among young women.

\section{Awareness of sexual and reproductive health matters}

Findings underscore young people's limited awareness of most sexual and reproductive matters, ranging from how pregnancy occurs to contraception, HIV and safe sex practices. For example, just $37 \%$ of young men and $45 \%$ of young women were aware that a woman can get pregnant at first sex, and 19\% and 15\%, respectively, of young men and women reported awareness of STIS other than HIV. Although awareness of HIV/AIDS was reported by the majority of young men and women, it was not universal, especially among young women (reported by $91 \%$ and $73 \%$ of young men and women, respectively). Likewise, although knowledge of the legal minimum age at marriage was reported by large proportions of youth, three of ten young men and four of ten young women did not know that 18 years is the legal minimum age at marriage for females.

While most youth had heard of contraception and HIV/AIDS, in-depth awareness was limited. For example, $95 \%$ of young men and women had heard of at least one modern method of contraception. However, correct knowledge of even one modern non-terminal method such

Percentage of youth by awareness of HIV/AIDS, comprehensive knowledge about HIV/AIDS and awareness of STIs

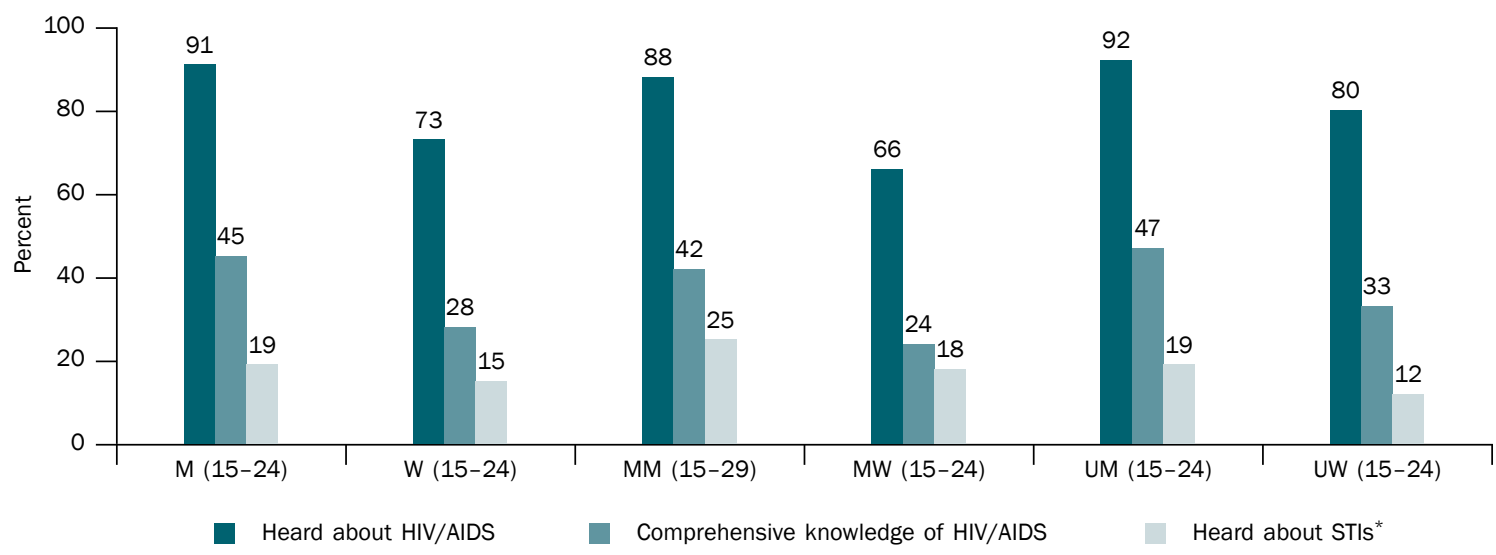

$\mathrm{M}=$ Men; $\mathrm{W}=$ Women; $\mathrm{MM}=$ Married men; $\mathrm{MW}=$ Married women; $\mathrm{UM}=$ Unmarried men; $\mathrm{UW}=$ Unmarried women

Note: * Other than HIV.

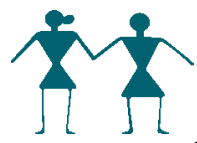


as the condom, the IUD, oral contraceptives and emergency contraception was reported by considerably fewer: $78 \%$ of young men and $49 \%$ of young women. Likewise, while $91 \%$ of young men and $73 \%$ of young women had heard about HIV/AIDS, just $45 \%$ of young men and $28 \%$ of young women had comprehensive awareness of HIV. Findings of considerable gender difference in comprehensive awareness about contraception and HIV/AIDS raise concerns about the vulnerability of young women.
Percentage of youth who received family life or sex education

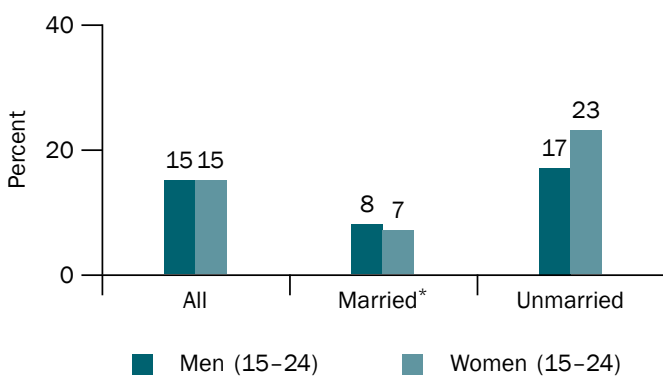

Note: *Married men (15-29).

Youth had few sources of information on sex and reproduction. Indeed, almost half of young women and one-sixth of young men reported that they had never received any information on sexual matters (prior to marriage among the married).

Leading sources of information on sexual matters were friends and the media for both young men and women. In contrast, just $10 \%$ of young men and women cited teachers and $3-7 \%$ cited health care providers as a source of information; just $2 \%$ and $9 \%$ of young men and women, respectively, cited a family member. Among the leading current sources of information on contraception among young people who were aware of at least one method were similarly, peers and the media, and, among young women, family members. Again, teachers and health care providers were relatively infrequently reported as such: Just $13-14 \%$ of young men and women

\section{Percentage of youth reporting knowledge of selected sexual and reproductive health matters} according to whether they had or had not received family life or sex education

Men (15-24)

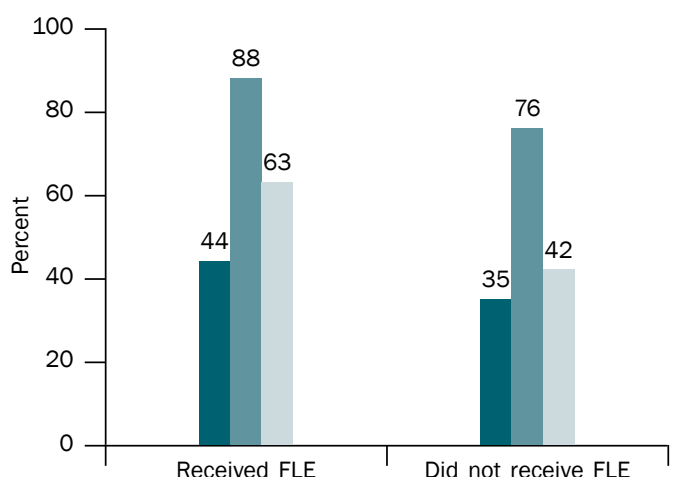

Women (15-24)

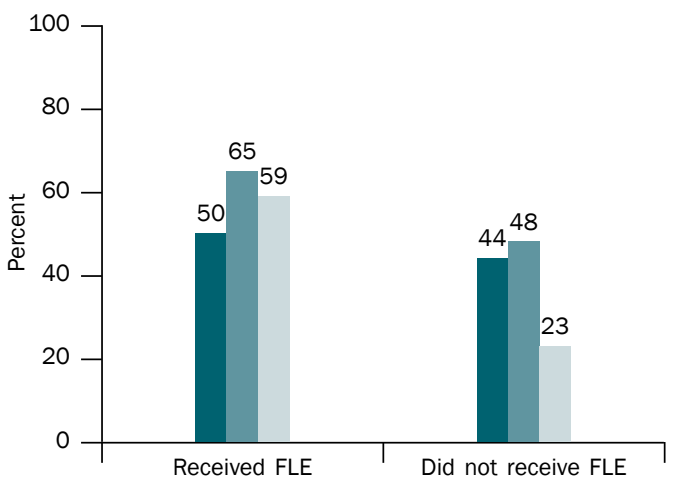

- Aware that a woman can become pregnant at first sex

- In-depth awareness of any contraceptive method

Comprehensive knowledge of HIV/AIDS

Note: FLE: Family life or sex education. 
had obtained this information from a health care provider and 7-9\% from a teacher. In short, health care providers, teachers and family members-often assumed to be more reliable sources of information than peers or the media - were infrequently and inconsistently cited by young people as sources of information on sensitive topics such as sexual matters and contraception.

Few youth - just 15\% - had attended family life or sex education programmes either in or outside the school setting, notwithstanding the Adolescence Education Programme, the School AIDS Education Programme, the Red Ribbon Clubs and special programmes for out-of-school youth in most Youth Study states. Indeed, even among the unmarried, just $17 \%$ of young men and $23 \%$ of young women reported exposure to family life or sex education. Further, although most (87-90\%) reported that many of their questions had been answered, one-fifth of young men (21\%) and almost two-fifths of young women (37\%) reported feelings of discomfort or embarrassment while receiving such education, raising questions about the extent to which they were indeed able to participate freely and clarify doubts. Despite this, youth were overwhelmingly in favour of the provision of family life or sex education to young people ( $83 \%$ of young men and $78 \%$ of young women); typically, young men preferred to receive this education from a teacher, while young women preferred to obtain it from either a family member or a teacher. Findings suggest, moreover, that youth who had undergone family life or sex education were indeed more knowledgeable about sexual and reproductive matters than those not exposed to it.

Finally, a regional pattern was not apparent with respect to young people's levels of awareness about such matters as correct specific knowledge of modern contraceptive methods, the legal minimum age at marriage, and perceptions about the condom. However, youth in Maharashtra and the southern states were, by and large, more likely to report awareness of such matters as medical abortion, the fact that sex selective abortion is illegal, STIs other than HIV/AIDS and comprehensive awareness of HIV/AIDS. They were, moreover, more likely to have received family life or sex education.

\section{Pre-marital romantic relations}

Findings confirm that despite strict norms prohibiting pre-marital opposite-sex mixing, opportunities do exist for the formation of pre-marital romantic relationships. Indeed, significant minorities of young men and women had made or received a "proposal" for a romantic relationship (21-23\%), and noteworthy, if smaller, percentages reported that they had been involved in a romantic partnership (19\% and $9 \%$ of young men and women, respectively). Patterns of pre-marital romantic partnerships suggest that where partnerships occurred, they were initiated at an early age and were usually hidden from parents but not from peers. The majority of youth who engaged in a pre-marital romantic partnership had expectations of a longer-term commitment; young women were considerably more likely than young men to have expected a romantic relationship to lead to marriage ( $87 \%$ and $57 \%$, respectively). The experiences of the married suggest, moreover, a disconnect between intentions and reality: 
Percentage of youth who had made or received a "proposal" for romantic partnership formation and percentage who had an opposite-sex romantic partner

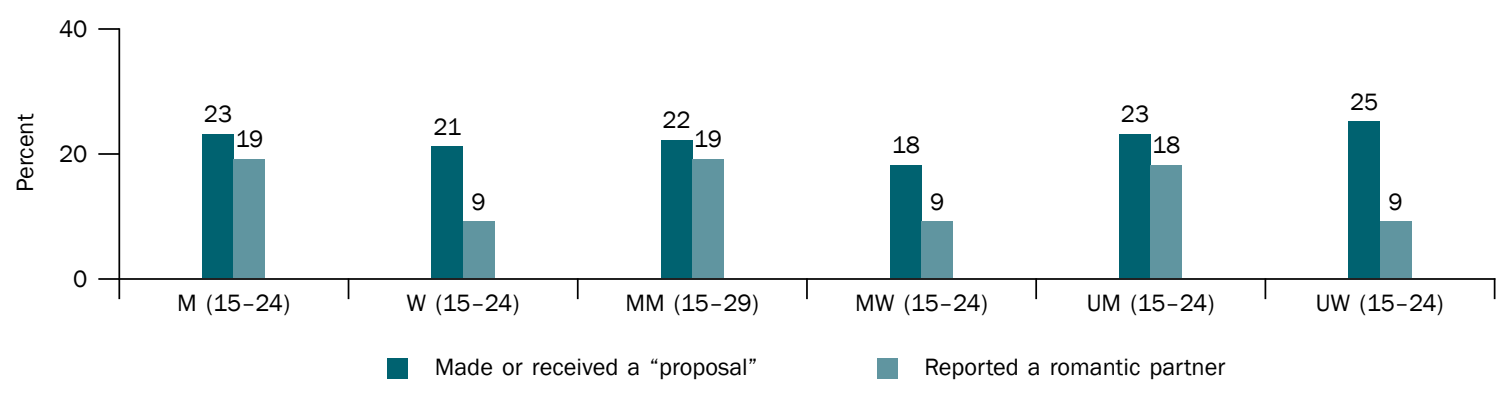

M=Men; $W=$ Women; $M M=$ Married men; MW=Married women; UM=Unmarried men; UW=Unmarried women

while $64 \%$ and $92 \%$ of married young men and women who reported a pre-marital romantic partner, respectively, had intended to marry their pre-marital partner, far fewer (23\% and $64 \%$, respectively) had done so.

There was a clear progression in reported physical intimacy and sexual experience with romantic partners: while $88 \%$ of young men had held hands with a romantic partner, just $42 \%$ had sex with their partner; among young women, while three-quarters had held hands with a romantic partner, just one in four (26\%) had engaged in sexual relations. Gender differences in reporting pre-marital sex with a romantic partner were indeed wide. Partner communication and negotiation regarding safe sex were rare, and the vast majority of youth had engaged in unprotected sex. One in seven young women who had sex with an opposite-sex romantic partner reported that their partner had forced them to have sex the first time.

\section{Pre-marital sexual experiences in romantic and other relationships}

In total, $15 \%$ of young men and $4 \%$ of young women reported experiences of pre-marital sex within romantic and/or other partnerships. Young men tended to initiate pre-marital sex earlier than young women; moreover, youth in rural areas tended to initiate pre-marital sexual activity earlier than their urban counterparts. Also, initiation of pre-marital sexual activity increased as young people transitioned from early into late adolescence, and further into young adulthood. Although a regional pattern was not evident with regard to pre-marital sexual experience, some state-wise differences were evident. Among young men, those in Tamil Nadu were less likely than those in the remaining five states to report pre-marital sex (9\% versus $14-17 \%$ ). Among young women, those from Jharkhand and Andhra Pradesh were more likely than those from the other states to report pre-marital sex (6-7\% versus $2-3 \%)$, and this pattern held, irrespective of marital status and rural-urban residence.

While sex with a romantic partner characterised pre-marital experiences for many of the sexually experienced, findings suggest that young men, but not young women, also engaged in sex in 
Percentage of youth reporting pre-marital sex, according to residence

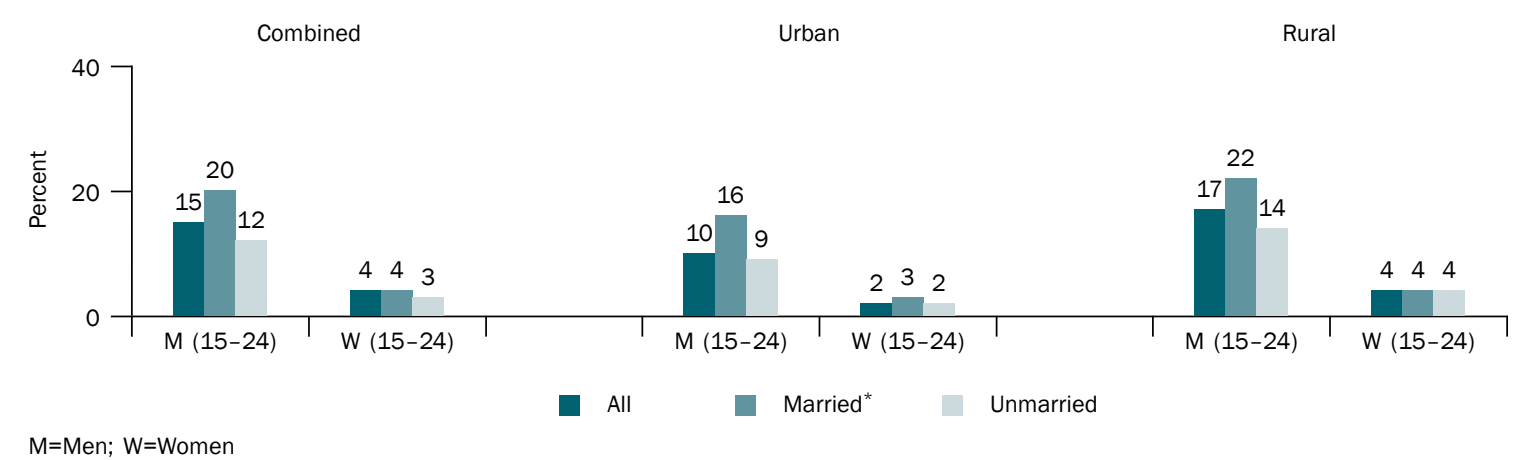

Note: *Married men (15-29).

other contexts; other partners reported by young men included, mainly, married women, but also sex workers and casual partners. Many of the pre-marital sexual experiences reported by youth were risky, for example, $25 \%$ of young men and $21 \%$ of young women reporting pre-marital sex had sex with more than one partner. Moreover, consistent condom use was limited-only $13 \%$ of young men and $3 \%$ of young women reported condom use in all pre-marital encounters. While sexual relations were generally unsafe across all the six states, some notable state-level differences were discerned. For example, among young men, multiple partner relations were reported by $22-32 \%$ in five of the six states, but by relatively few (14\%) in Rajasthan. Consistent condom use was most likely to be reported, however, by young men in Maharashtra and

\section{Percentage of youth reporting pre-marital sex by state}

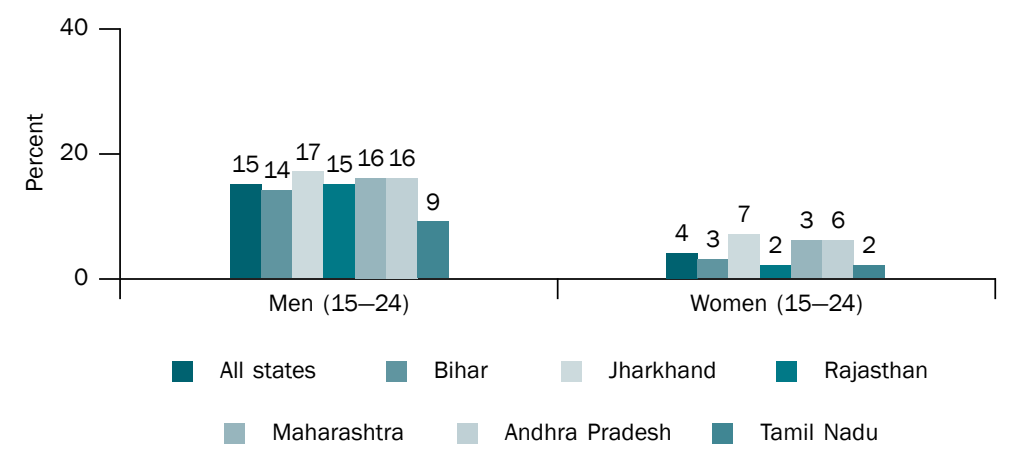

Andhra Pradesh (17-22\% compared to $5-7 \%$ in the remaining four states). Among young women, those from Andhra Pradesh were less likely than those from the remaining states to report pre-marital sex with multiple partners (7\% versus $28-33 \%)$; differences were muted with regard to consistent condom use.

We acknowledge that youth, especially young women, may not report their sexual experiences in a survey situation. Hence, the Youth Study supplemented a series of direct questions with an opportunity to report sexual experiences in an anonymous format. Overall, it would appear that the sealed envelope technique did indeed offer a considerable number of sexually active young men and women who opted not to disclose their sexual experiences in face-to-face questioning the opportunity to do so. 


\section{Transition to marriage and early married life}

Findings indicate that although most youth preferred to marry after age 18 , as many as $19 \%$ of young women aged 20-24 were married before age 15, 49\% before age 18, and $67 \%$ before age 20. In contrast, just 7\% of young men aged 20-24 were married before age 18 and 16\% before age 20 .

Not only did marriage occur at young ages but it was also often arranged without the participation of young people themselves, particularly young women. Almost all youth reported arranged marriages. As many as one in ten young men and one in four young women reported that their parents did not seek their approval while determining their marriage partner. Hence, not surprisingly, reported pre-marital acquaintance was limited. Just one in five young men and one in seven young women reported that they had ever had a chance to meet and interact with their spouse-to-be alone prior to marriage. About two in

Percentage of youth aged 20-24 who were married before selected ages

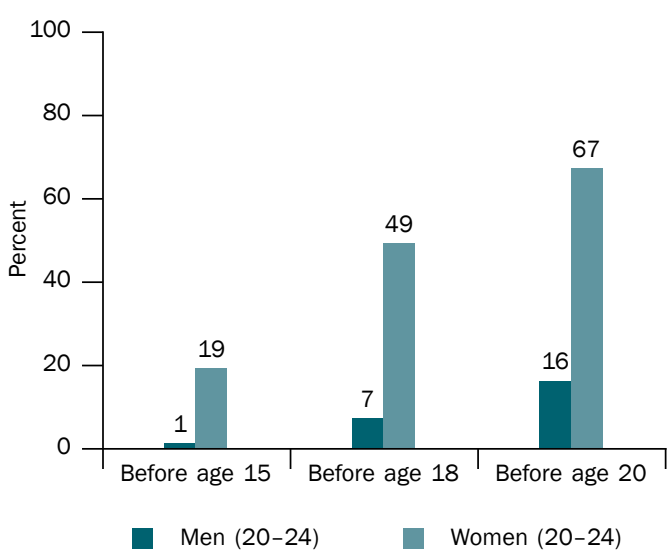
three married youth reported that they had met their spouse for the first time on the wedding day. Compounding the lack of pre-marital acquaintance was the lack of awareness of what to expect of married life, reported by $70 \%$ of young men and $78 \%$ of young women.

Despite the existence of laws against the payment of dowry, this practice characterised the marriages of about three-quarters of young men (72\%) and women (78\%). Findings also show that families of urban youth were as likely as their rural counterparts to conform to traditional practices, such as the payment of dowry.

\section{Percentage of married young women reporting experience of sexual and physical violence perpetrated by their husband and percentage of married young men reporting perpetration of sexual and physical violence against their wife}

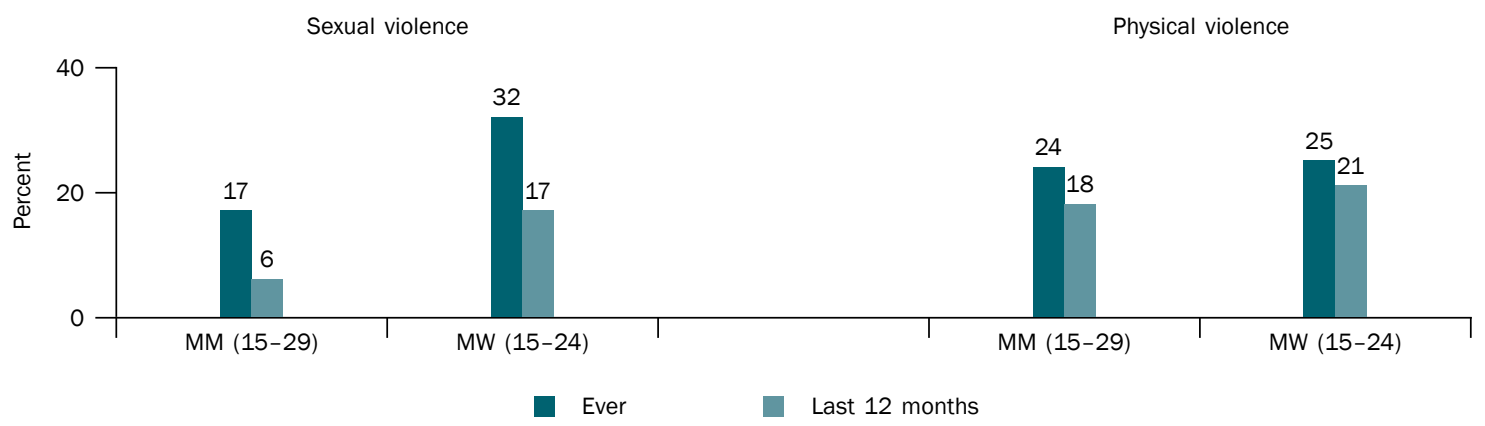

$\mathrm{MM}=$ Married men; MW=Married women 
Reports of marital life suggest that spousal communication was far from universal and that marital life was marked by considerable violence. For example, couple communication on contraceptive use was reported by just $34 \%$ of young men and $55 \%$ of young women, clearly undermining married young people's ability to adopt protective actions. Physical violence and forced sex within marriage were reported by considerable proportions of youth; of note is the finding that considerably more young women reported the experience of sexual compared to physical violence. For example, one-quarter of young women reported that they had ever faced physical violence perpetrated by their husband (25\%) and a similar percentage of young men (24\%) reported perpetrating violence on their wife. Recent violence was reported by fewer: $18 \%$ of young men and $21 \%$ of young women. In contrast, one-quarter of young women reported that their first sexual experience within marriage had been forced, and one in three young women reported ever being forced to engage in sex by their husband; relatively fewer young men-about one in six-reported forcing their wife to engage in sex. Recent sexual violence was reported by $16 \%$ of young women and $6 \%$ of young men.

While the Youth Study did not explore extra-marital sexual experiences in detail, the available data indicate that $4 \%$ of young men reported an extra-marital sexual encounter. In contrast, hardly any young women reported so.

\section{Contraceptive practice and pregnancy experience}

Contraceptive use at any time within marriage was limited, reported by $24-25 \%$ of young men and women. Moreover, just $18 \%$ of youth reported current use of contraception. Reporting of methods currently used was fairly similar among young women and men. Contraceptive

Percentage of married youth reporting lifetime and current use of contraceptive methods within marriage

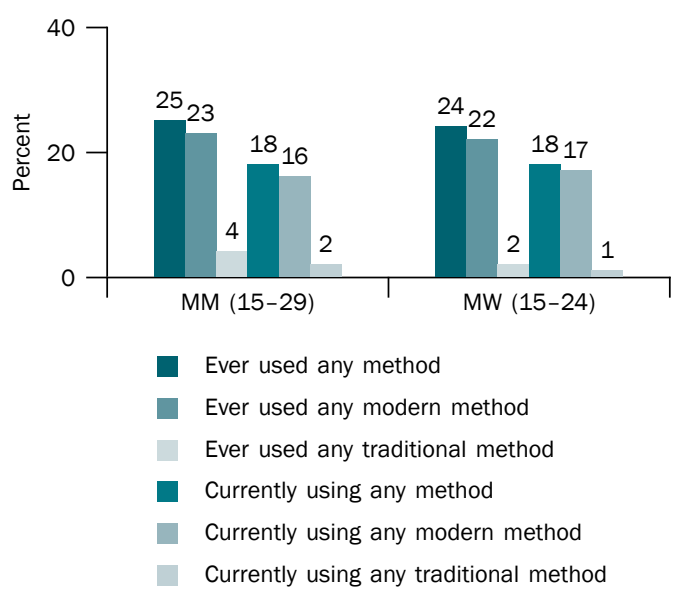

$\mathrm{MM}=$ Married men; $\mathrm{MW}=$ Married women methods most likely to be used were condoms and oral contraceptives and, notwithstanding their young age, female sterilisation. Few young people practised contraception to delay the first birth-just $12 \%$ of young men and $5 \%$ of young women. Not surprisingly, pregnancy typically occurred within a year of marriage for three-fifths of young women and young men who reported that they or their wife had been pregnant at least once. Moreover, large proportions of youth-particularly young women-reported experiencing unintended pregnancy. For example, among young women who were not pregnant at the time of the interview and young men whose wife was not pregnant at the time of the interview, $25 \%$ and $14 \%$, respectively, reported that the last pregnancy was mistimed or unwanted. 
Circumstances of the first birth suggest that institutional delivery and skilled attendance at delivery were limited: only about half of first births (47-54\%) were delivered institutionally and just two-thirds reported delivery by a skilled attendant.

Findings also show that son preference was evident. Almost one-quarter of young men and women preferred to have more sons than daughters. In contrast, just $3-5 \%$ preferred to have more daughters than sons.

Finally, findings suggest that transitions to marriage and parenthood were fraught with several challenges for all youth, but these challenges were, by and large, more daunting for youth from the northern states than for those from Maharashtra and the southern states. For example, marriage continues to take place in adolescence for large proportions of young women and significant minorities of young men in the northern states. Youth in the northern states were also more likely than their counterparts in Maharashtra and the southern states to have consented to marry without any involvement in selecting their marriage partner and to have met their spouse for the first time on the wedding day. Moreover, youth from the northern states were more likely than those from Maharashtra and the southern states to report forced sex, including at initiation. Notwithstanding these regional differences, no regional pattern was discernible in young people's reports of perpetration or experience of physical violence within marriage; indeed, youth in Tamil Nadu were more likely than those from most other states to report the perpetration and experience of physical violence, including in the 12 months preceding the interview.

With regard to utilisation of reproductive health services, findings suggest that youth from the northern states along with Maharashtra were more likely than those from the southern states to report practice of contraception to delay the first pregnancy. Youth from the northern states were also more likely than those from the other states to report three or more live births and less likely to report institutional delivery and skilled attendance for the first birth. Moreover, they were more likely to report son preference.

\section{Substance use}

Findings show that substantial proportions of young men reported the consumption of tobacco and alcohol; almost one-third of young men reported tobacco consumption and one-sixth reported alcohol consumption; almost all of these- $29 \%$ and $14 \%$, respectively-had done so in the month preceding the interview. As expected, few young women reported that they had consumed any of these substances. In contrast, hardly any young men and not a single young woman reported drug use. State-wise differences suggest that young men in Bihar, Jharkhand and Maharashtra were more likely than their counterparts from the other states to have consumed tobacco products in the month preceding the interview. In contrast, young men from the southern states were considerably more likely than those from the other states to have consumed alcohol in the month preceding the interview (22\% versus $6-16 \%$ ). 


\section{Health seeking behaviour}

Although youth is a generally healthy period of life, significant minorities reported experiencing general, mental, and sexual and reproductive health problems in the period preceding the interview. For example, $21 \%$ of young men and $32 \%$ of young women had experienced high fever, and $5 \%$ of young men and $17 \%$ of young women reported the experience of symptoms of genital infection. One in eight young women reported experiencing menstrual problems; at the same time, almost one-quarter of young men reported anxiety about nocturnal emission. Finally, responses indicative of mental health disorders were reported by one in seven young men and women. Findings, moreover, suggest that young men in Bihar and Jharkhand were more likely than those in the other states (16-28\% versus 11-13\%), and young women in Jharkhand, Rajasthan and Maharashtra were more likely than those in the other states (17-21\% versus 9-10\%) to report symptoms or behaviours suggestive of mental health disorders.

With regard to care seeking for general and sexual and reproductive health problems, patterns varied by type of problem. While the large majority of those who had experienced high fever, for example, had sought care, many fewer had sought care for sexual and reproductive health problems. Of those who had sought treatment, large proportions of young men and women had sought advice or treatment from a private facility or provider, irrespective of the type of problem. However, in the case of anxiety about nocturnal emission, young men had rarely sought advice from a health care provider, preferring to do so from their peers.

Findings suggest that youth were shy about seeking sexual and reproductive health services. For example, many youth, including the married, reported that they would indeed hesitate to approach a health care provider or a pharmacy/medical shop for contraceptive supplies.

Finally, small minorities of young men (4\%) and somewhat more young women (11\%) reported that they had undergone HIV testing. While state-wise differences were narrow among young men, young women from Maharashtra and the southern states were more likely than those from the northern states to have undergone an HIV test (6-24\% versus 1-3\%). Findings, moreover, suggest that youth were overwhelmingly in favour of pre-marital HIV testing. While no regional pattern was discernible among young men, young women from Maharashtra and the southern states were somewhat more likely than their northern counterparts to favour pre-marital HIV testing.

\section{Participation in civil society and political life}

Findings highlight the limited participation of youth in civil society. Although a number of programmes are organised by the government or NGOs at the community level in which youth can participate, few youth ( $22 \%$ of young men and $31 \%$ of young women) reported familiarity with these programmes. Even fewer youth—12\% of young men and $9 \%$ of young women-reported 
participating in such programmes. Relatively larger proportions of young men (45\%) and young women (15\%) reported that they had participated in community-led activities such as the celebration of festivals and national days. Finally, just 10-11\% of young men and women reported membership in organised groups.

Regional patterns in the extent of participation in civil society and political life were marked. For example, young men and women in Maharashtra and the southern states were considerably more likely than those from the northern states to report awareness of government and NGO-sponsored programmes as well as participation in these programmes. They were also more likely to report participation in community-led programmes and membership in organised groups. A similar pattern was observed with regard to the expression of secular attitudes: Youth in Maharashtra and the southern states were consistently more likely to express secular attitudes than their northern counterparts.

Findings suggest that large proportions of youth did indeed vote, however voting behaviour was far from universal. Among those eligible, $71 \%$ of young men and $60 \%$ of young women had cast their vote in the most recent election preceding the interview for which they were eligible to vote. Large majorities of youth (83-86\%) perceived that one could vote freely and without fear and pressure. At the same time, however, considerable proportions reported dissatisfaction with the political process: $68 \%$ of young men and $57 \%$ of young women reported disillusionment with the commitment of political parties to work for change at the community level.

Regional patterns were less evident with regard to political participation. However, youth from the southern states were more likely than those from the northern states to perceive that one could vote freely and without fear or pressure. Considerable proportions of youth from all the six states reported disillusionment with the political process.

Expressions of secular attitudes varied. About three-fifths (63\%) of young men and half (51\%) of young women reported that they would mix freely with individuals of different religions and castes, would eat together with a person of a different caste or religion, and would talk to a person who has had an inter-caste marriage. Findings suggest a consistent positive association between age, education and wealth status, and expression of secular attitudes. They also suggest that youth from Maharashtra and the southern states were consistently more likely to express secular attitudes than their northern counterparts. 
Considerable proportions of young men and women acknowledged that physical fights among young men and also among young women did occur in their village or urban neighbourhood; however, just $11 \%$ of young men and $3 \%$ of young women reported that they had been involved in a physical fight in the year preceding the interview.

The four leading problems facing youth expressed by both young men and women were unemployment, poverty, lack of amenities and lack of educational opportunities. However, young people's perceptions of these problems varied enormously by sex. Among young men, the majority reported difficulty in finding employment as the leading problem, followed by concerns about poverty more generally, lack of amenities or infrastructure and lack of educational opportunities. In contrast, the leading problem expressed by young women was lack of amenities and infrastructure, and to a lesser extent, difficulty in finding employment, poverty more generally, and lack of opportunities for education. This pattern persisted fairly uniformly in all the six states.

\section{Recommendations for programmes}

Findings presented in the sections above underscore the fact that youth face numerous challenges while making the transition to adulthood. These challenges call for programme interventions at the youth, family and service delivery levels. Key programme recommendations emerging from this study are highlighted below.

\section{Address obstacles to universal school enrolment and secondary school completion}

Youth Study findings highlight that school enrolment was far from universal among young people in the country and that school completion rates were low. Concerted efforts are needed if the country is to achieve the Millennium Development Goal of ensuring universal primary school completion. While the achievement of universal primary school completion is a key goal, the importance of high school education in enabling youth to make a successful transition to adulthood underscores the need, at the same time, for efforts to overcome barriers to high school completion. The government has articulated its commitment to improving the schooling situation in the country in several policies and acts, including the recently enacted Right of Children to Free and Compulsory Education Act 2009, and through several programmes, including the Sarva Shiksha Abhiyan, the Rashtriya Madhyamik Shiksha Abhiyan and the Saakshar Bharat scheme. What is needed is a strong commitment to ensuring that these programmes are effectively implemented and that these do indeed reach the most disadvantaged groups.

A number of factors have been identified in the Youth Study that inhibit school completion; leading among these were economic reasons; attitudes and perceptions and school-related reasons; and, among young women, house-work and marriage related reasons as well. Multiple activities are needed to address these barriers. Efforts must be made, for example, to address the economic pressures that dissuade parents from enrolling their children in school and from 
keeping them in school once enrolled. A number of centrally- and state-sponsored programmes are ongoing that aim to reduce the cost of education and it is important to ensure that these ongoing government programmes do indeed reach the most disadvantaged groups; additional inputs, by way of conditional grants that encourage school completion among disadvantaged groups, also need to be considered. At the same time, activities directed at parents are needed that promote positive attitudes towards education and school completion, raise their aspirations about their children's education and encourage greater parental involvement in their children's education.

Activities must also address school-level barriers, notably, poor infrastructure, quality of education and academic failure, particularly among young women. Several state governments have launched various schemes to address these barriers (for example, the bicycle schemes for girls in Jharkhand and Bihar); however, it is important that the effectiveness of these schemes is evaluated and promising lessons are assimilated and scaled up. There is a need to incorporate livelihood skills building models within the school setting that will not only raise young people's aspirations regarding their education and careers but also provide them opportunities to gain market-driven job skills. There is also a need to focus on providing better training and ensuring accountability for teachers-investments that are likely to improve the quality of schooling experiences for youth. Finally, given the large proportions reporting that schooling had been interrupted because they were required for work on the family farm or business or for housework, and given the reality of young people's lives and the economic pressures on families, efforts need to be made to adjust school timings, including the establishment of evening schools to enable children to accommodate work on the family farm or business without sacrificing their education.

Findings indicating the transition to adult roles, particularly early marriage, as an important reason for school discontinuation among girls emphasise the fact that programmatic commitments outside the education sector are also critical to the achievement of universal school enrolment and completion. Specifically required are programmes that seek to critically examine norms and practices surrounding marriage and to eliminate the practice of early marriage. Explorations of subsidies and cash transfers that link school retention and delayed marriage among girls are needed.

Findings that several sub-groups of youth-young women, the married, the rural, those belonging to poor households, Muslim youth and those belonging to scheduled castes and tribes-remain considerably disadvantaged call for efforts that specifically target these vulnerable groups. Interventions are needed that give youth who missed the opportunity to obtain adequate formal education a second chance to acquire equivalency to formal education.

Finally, findings indicating considerable state-wise differences in school enrolment and completion call for state-specific interventions. Targeted efforts to achieve universal school enrolment and at least primary school completion need to be a high priority in the northern states, while concerted efforts to achieve universal secondary school completion are called for in Maharashtra 
and the southern states. At the same time, efforts to provide a second chance to youth who missed the opportunity to acquire an adequate level of formal education are called for in all the six states.

\section{Strengthen efforts to prevent child labour}

Findings of the Youth Study that over one in four young men and women had initiated work in childhood or in early adolescence (before age 15) reiterate the recommendation highlighted above regarding the need to provide conditional grants and targeted subsidies to disadvantaged groups, which would encourage parents to opt for schooling over work for their children. At the same time, it is important to vigorously enforce existing laws that prohibit child labour. Such efforts are particularly needed in Andhra Pradesh, Bihar, Jharkhand and Rajasthan.

\section{Invest in promoting youth employment}

Findings point to the effective unemployability of significant proportions of youth. For example, few youth-two in five young men and one in three young women-had completed high school. Even fewer-one-fifth of young men and a quarter of young women-had attended a vocational training programme. It is notable that while considerable proportions of urban youth reported exposure to computer skills, English language skills and so on, rural youth tended to opt for relatively traditional vocational skills and may not have had the opportunity to learn about market needs or develop appropriate skills for which a demand exists. It is also notable that those who were engaged in economic activity were working largely as agricultural and unskilled non-agricultural labourers. Moreover, considerable proportions of youth, particularly, the educated were unemployed, suggesting a possible disconnect between youth skills and market needs.

The country must significantly strengthen investments in programmes that enable youth to make a successful transition to work roles. Enhancing employability would depend to a considerable extent on the improvements in educational attainment discussed above; it would also require greater investment in enabling youth to acquire vocational skills. Formal mechanisms must be developed that provide opportunities to youth to acquire skills for which there is an established demand, and that link eligible youth to market opportunities. The proposed National Skills Development Initiative is a step in the right direction and it is important that this initiative is implemented without any delay. At the same time, efforts are needed to promote self-employment and entrepreneurship through various livelihood schemes, for example, providing soft loans to youth to enable them to set up their own business enterprises. Also required are efforts to evaluate existing programmes aimed at job creation to assess their reach and impact in enabling young people to make a successful transition to work roles, upscale successful models, raise awareness among youth about their availability and ensure that these programmes do indeed reach young people. Findings highlighting young women's particularly limited access to wage work call, moreover, for programmes specially targeted towards young women. 
Finally, findings indicating considerable state-wise differences in unemployment rates and young people's participation in vocational training programmes call for state-specific interventions. Concerted efforts to improve the employability of youth and to enhance the reach of existing programmes aimed at job creation among youth are most urgently required in states like Bihar, Jharkhand and Rajasthan. At the same time, efforts to meet the large unmet need for vocational skills training are needed in all the six states.

\section{Promote agency and gender equitable norms among youth}

Findings highlight the limited agency of young women and the persistence of gender double standards among youth. Young women were particularly disadvantaged in terms of school enrolment, attendance and completion, participation in wage earning activities, and exposure to mass media. While young women were as likely as young men to have participated in vocational training programmes, most young women had undergone training in traditional skills, such as tailoring and handicrafts. Socialisation was gendered and parental control over their adolescent children's mobility and interactions with peers was stricter for young women than men. Additionally, compared to young men, young women reported less mobility, opportunities to build peer networks, decision-making authority in matters relating to their own lives and control over resources. And although young women were more likely than young men to express equitable gender role attitudes, over half of both young men and women expressed traditional attitudes concerning wife beating. These findings call for attention to promote life skills education programmes for young women, both unmarried and married, that will not only raise their awareness of new ideas and the world around them but also enable them to put new information into practice, encourage them to question gender stereotypes, develop self-esteem and strengthen their skills in problem-solving, decision-making, communication and inter-personal relations and negotiation. Equally important is to identify safe spaces in which young women can build social networks and find social support among peers.

Interventions intended to build life skills must also be inclusive of young men. Indeed, findings that inegalitarian gender role attitudes were expressed by many young men, on the one hand, and that considerable numbers of young men were not able to exercise agency in their everyday lives, on the other, call for programmes that build their life skills, promote new concepts of masculinity and femininity and at the same time, promote messages that build egalitarian relations between women and men.

Promoting gender equitable norms and practices requires active engagement with the community. It is essential that programmes for youth work with key community members, such as parents and political and religious leaders in the community, to critically examine prevailing gender norms and forces that perpetuate such norms. 
An increasing number of intervention models to build agency and promote egalitarian gender role attitudes among young people have been tested in India. These models could be reviewed and replicated or scaled up as appropriate.

\section{Provide opportunities for formal saving, especially for young women}

Findings suggest that while young women were more likely than young men to report savings, they were somewhat less likely to own a savings account, and, among those who did own an account, considerably less likely to operate the account independently. At the same time, few youth owned a bank or post office account. Programmes are needed that inculcate a savings orientation among young people, that offer savings products that are attractive and appropriate to the small and erratic savings patterns of young people and that enable young women in particular to overcome obstacles related to owning and controlling savings products.

\section{Promote youth participation in civil society and political processes and reinforce secular attitudes}

Findings note that large proportions of youth have exercised their right to vote, that the majority hold secular attitudes with regard to mixing with a person from another caste and religion, and few engage in community-level violence. Nevertheless, not all youth expressed secular attitudes. Moreover, considerable proportions of youth were dissatisfied with the political process. Finally, relatively few had taken part in civil society, that is, government- or NGO-sponsored programmes or community-led activities.

Programmes are needed at the school, college and community levels-through national service programmes, sports and other non-formal mechanisms-that encourage civic participation, incorporate value building components and reinforce secular attitudes and values that espouse responsible citizenship. Findings indicating that youth participation in civil society and the expression of secular attitudes were far more limited in the northern states than in Maharashtra and the southern states emphasise that these programmes should be a high priority, especially in the northern states.

Findings also emphasise that the political system in the country needs to make special efforts to address the concerns of youth and encourage youth participation in the political processes in more meaningful ways. Such efforts are called for in all the states.

\section{Strengthen family life or sex education for those in school and out of school}

The provision of family life or sex education to young people has been a controversial issue in the country. Youth Study findings provide considerable evidence suggesting that family life or sex education is urgently needed for youth, both for those in school and those who have discontinued their education. Findings demonstrate a limited understanding of sexual and 
reproductive matters among young people, including the married. Misconceptions abound on most topics: sex and pregnancy, contraceptive methods including condoms, STIs and HIV/AIDS and the conditions under which abortion is legally available or restricted. Where awareness of sexual and reproductive health matters exists, it is superficial in many cases. Moreover, substantial proportions of married young women (and some young men) reported entering marriage completely unaware of what marriage entailed. At the same time, several young people had engaged in pre-marital sexual relations uninformed about risk taking and safe practices. Finally, youth themselves have called for family life or sex education.

Programmes are ongoing in several Youth Study states that aim to impart sexual and reproductive health information to young people. What is needed is a strong commitment to ensuring that these programmes do indeed reach young people, both those in school and out-of-school, married and unmarried, and rural and urban. At the same time, it is important that such programmes are revived in states in which they have been stalled. These programmes should be age-appropriate. Moreover, there is a need to expand the content of existing awareness raising programmes to include not just HIV-related information but broader sexual and reproductive health topics. These programmes should be designed not only to raise awareness among youth but also to enable young people to correctly understand and assess the risks they face and to adopt appropriate protective actions.

In addition, special attention needs to be paid to the training of trainers. Indeed, findings indicate that one in three young women and one in five young men who had received formal family life or sex education reported feeling uncomfortable or embarrassed in the course of receiving this information, raising questions about the extent to which youth were indeed able to participate freely in discussions and clarify their doubts. At the same time, these findings raise questions about the ability of trainers to connect with youth to whom they provided this education. Such findings clearly highlight the need to improve the quality of training imparted to trainers. It is important that teachers, health care providers and other experts undergo training that enables them to overcome their reluctance to communicate with youth on sensitive sexual and reproductive matters, dispels their misconceptions on these matters, and enhances both their communication skills and their technical knowledge of these issues. Peers and, in the case of young women, parents have also been identified as acceptable sources of information and efforts must therefore be made that identify youth leaders and build networks of peer educators. Also needed are efforts to engage parents-providing them with accurate information and working with them to overcome inhibitions about imparting this information to their children, particularly their daughters.

\section{Ensure that when pre-marital sex takes place, it is safe and wanted}

While sexual activity is initiated within the context of marriage for the vast majority of young women, findings show that a sizeable proportion of young men and some young women had engaged in sex before marriage. As documented in this report, many youth had initiated sexual 
activity uninformed, reiterating the need for providing age appropriate family life or sex education to young people. Moreover, the finding that for many youth, pre-marital sexual experiences were unsafe, and for some unwanted, calls for programmes that focus not only on building sexual and reproductive health awareness among young people but also on enabling them to correctly understand and assess the risks they face, and developing their skills in negotiating safe sex and communicating with their partners on sexual and reproductive health matters. At the same time, programmes must make available appropriate family planning and infection prevention services for unmarried young men and women in a manner acceptable to them.

\section{Intensify efforts to eliminate the practice of early marriage}

Findings indicate that although most youth prefer to marry after age 18, the practice of early marriage is widespread among young women. These findings call for measures that go beyond information campaigns to address the underlying factors-social norms and economic constraints-driving early marriage in the country.

There is a need for a multi-pronged approach to eliminate the practice of early marriage. Strategies are needed that mobilise communities to help parents resist pressures that foster the practice of early marriage. Moreover, strategies are needed that establish new norms and practices, that actively engage influential persons in the community, including religious and political leaders, as well as that initiate campaigns highlighting the adverse consequences of early marriage and the extent to which it is a violation of the rights of the child. Finally, strategies for community mobilisation must involve youth themselves as well as their families.

Equally important is to ensure greater commitment on the part of law enforcement agencies to enforce existing laws on the minimum age at marriage and the registration of marriages, and to levy penalties on violators. Allowing anonymous reporting, making law enforcement agencies and others aware that the practice of early marriage is not a minor violation, and making the guidelines for penalties clear to enforcement agencies and the wider community are possible steps in this direction.

Efforts to delay marriage also require providing girls with viable alternatives to marriage in the form of accessible and quality schooling and opportunities to build and use livelihood skills. Working with the education sector to make schooling for girls more accessible, and to make classrooms gender-sensitive and responsive to the needs of girls and the concerns of their parents is important. At the same time, it is necessary to provide livelihoods training within and outside the educational system.

Findings that marriages were often arranged without the participation of young people themselves and that few young people had an opportunity to meet their spouse-to-be prior to the wedding day call for actions to sensitise parents to the need to involve their children in marriage-related decisions and enable them to interact with their prospective spouse prior to the wedding day. 
Parents must also be made aware of the physical and mental health consequences of early marriage and the adverse experiences of many young women (and some young men) who were married early or who were unprepared for marriage.

Finally, findings suggest that challenges faced by youth during transitions to marriage and parenthood were more daunting for those from the northern states than from Maharashtra and the southern states. For example, marriage continues to take place in adolescence for large proportions of young women and significant minorities of young men in the northern states. Youth in the northern states were also more likely than their counterparts in Maharashtra and the southern states to have consented to marry without any involvement in selecting their marriage partner and to have met their spouse for the first time on the wedding day. These findings emphasise that the strategies discussed above need to be accorded a high priority in the northern states.

\section{Support newly-weds to postpone the first pregnancy and promote pregnancy-related care among those who become pregnant}

Findings show that the social pressure to bear children as soon as possible following marriage persists. Contraceptives were rarely used to postpone the first pregnancy and many young women experienced their first pregnancy soon after marriage. It would appear that numerous forces work against delaying the first pregnancy-young people's lack of awareness of appropriate methods of contraception and access to supplies, overwhelming pressure from the family and the community to bear children as soon as possible after marriage, young people's limited skills in countering social expectations and negotiating pregnancy postponement, and the lack of attention from health care providers.

Programmes are needed that inform youth about their pregnancy postponement options and enable them to access appropriate contraception. At the same time, providers, including such outreach workers as ASHAs, must be trained and charged with the responsibility of reaching married young women and men-including those who have not yet experienced pregnancy-with information regarding contraception and other reproductive health matters as well as contraceptive supplies. Many married young women lack the freedom of movement to seek health care, underscoring the need for health workers to reach these women-particularly those newly married and first time pregnant-in their homes.

Findings indicating young women's limited access to maternal health services, even at the time of the first-often the most risky-pregnancy, highlight the need for reproductive and child health programmes in the country to build a demand for, as well as improve the availability of such services among young people.

Finally, findings that utilisation of reproductive health services by youth varied considerably across the states call for tailoring the focus of the programme in response to the situation and 
needs of youth in each state. For example, while the practice of contraception to delay the first pregnancy was limited in all the states, it was far more limited in the southern states than in Maharashtra and the northern states. In contrast, youth from the northern states were more likely than those from Maharashtra and the southern states to report three or more live births and less likely to report institutional delivery and skilled attendance for the first birth. The reproductive and child health programmes should take cognizance of these differences in the situation and needs of young people.

\section{Address power imbalances within marriage}

Findings regarding the multiple vulnerabilities faced by married young women underscore the need for programmes that support young women, especially the newly-wed, acknowledging that their situation and needs may differ from those of unmarried young women and married adults. Married young women typically have just a few years of schooling, limited exposure to mass media and limited mobility. They also have limited communication with their husband and notable proportions have experienced physical and sexual violence perpetrated by their husband.

Efforts are needed to encourage couple communication on sensitive issues (contraception, for example), negotiation and conflict management skills early in marriage. Efforts are also needed to inform married young women of their rights so that they have the opportunity to exercise control over their own lives; at the same time, efforts must be made to promote new concepts of masculinity and femininity and egalitarian couple relations among young men and women. Intervention models exist in India that have attempted to address these needs; these should be reviewed and up-scaled as appropriate.

\section{Engage boys and young men}

While wide gender disparities place young women at a notable disadvantage, Youth Study findings highlight that young men are also disadvantaged in many ways. Almost three-fifths had not completed high school and over one-quarter had initiated economic activity from an early age. Although socialized with more freedom than their sisters, communication with parents was limited among young men and many did not have decision-making authority in matters pertaining to their life or control over economic resources. Moreover, many were exposed to tobacco products and alcohol, many had experienced unsafe pre-marital sex, and notable minorities had married in adolescence. Awareness of sexual and reproductive health matters was limited, few had received family life or sex education, and many, including the married, reported discomfort about seeking contraceptives from a health care provider or pharmacy. Finally, as noted earlier, many held unequal gender norms, and power imbalances were evident within marital relations. These findings highlight that young men are vulnerable-albeit in different ways than young women-and argue that programmes for adolescents and young people must be inclusive boys and young men. 


\section{Create a supportive family environment}

Findings highlight the limited interaction and social distance between parents and young people while growing up and the gendered nature of socialisation experiences. Efforts must be made to create a supportive environment for young people. While evidence on models that are effective in bridging the distance between parents and children or that enable parents to adopt more gender-egalitarian socialisation practices is not currently available, findings presented in this report call for programmes that address parental inhibitions about discussing sexual matters with their children, encourage greater openness and interaction between parents and children, and enable the adoption of gender-egalitarian child-rearing practices. Programmes that aim to encourage universal education or eliminate child marriage must, likewise, address parental concerns about the potential consequences of keeping daughters in school or delaying their marriage.

\section{Reposition the condom as a suitable method for youth}

Findings have suggested that consistent condom use was rarely practised by those reporting pre-marital sexual relations, and few married youth reported the use of condoms at the time of the interview. At the same time, widespread misconceptions prevailed about the condom, including that it can slip off and disappear into the woman's body, and in-depth awareness about the condom was far from universal, especially among young women. Moreover, large proportions of youth reported discomfort about seeking contraceptives, including condoms, from a health care provider or pharmacy. Given the appropriateness of the condom for use among young people, it is important that bold and imaginatively designed communication programmes aimed at youth are implemented that dispel misconceptions and encourage condom use; and at the same time, that bold and imaginative changes are made in the service delivery structure that enable youth to access condoms easily and confidentially.

\section{Reorient service provision to address the unique sexual and reproductive health needs of unmarried and married young women and men}

Although the RCH Programme has advocated special services for youth, including the unmarried, these services had not reached the youth in our survey. For example, relatively small percentages of young people had ever practised contraception. Few had sought care for symptoms of STIs or gynaecological problems, and most youth who had sought care preferred private to public sector facilities. Lack of care seeking and the disconnect between the public health sector and youth underscore the need to sensitise health care providers about the special needs, heterogeneity and vulnerability of unmarried and married young women and men, and to orient them to the need for developing appropriate strategies to reach these diverse groups, including newlyweds. It raises, at the same time, the need to explore the feasibility of implementing various financing strategies, for example, health insurance, competitive voucher schemes and community financing schemes, which will allow youth to have a wider choice of providers and enhance the possibility of obtaining quality care. 
Programmes must be inclusive of unmarried as well as married young people and recognise their need and right to sexual and reproductive health and related information and services. Counselling and contraceptive services must be made available to all young people, including the unmarried, in a non-threatening, non-judgmental and confidential environment. Indeed, these findings call for the implementation of strategies outlined under the National Rural Health Mission's RCH Programme.

\section{Establish systems that address young people's mental health}

Findings that one in seven young men and women reported symptoms or behaviours suggestive of mental health disorders suggest that there is a need to establish systems that address young people's mental health. It is important that the National Mental Health Programme must take note of these findings and incorporate a special focus on identifying and treating youth in need. Efforts are needed to screen young people-particularly the rural among whom symptoms were more likely to be reported-for possible mental health disorders when they avail of other primary health services, including, for example, sexual and reproductive health services, and to refer youth with such symptoms to appropriate health facilities and providers. Findings that young men in Bihar and Jharkhand were more likely than others, and young women in Jharkhand, Rajasthan and Maharashtra were more likely than others, to report symptoms suggestive of mental health disorders highlight the need for such efforts on a priority basis in these states.

\section{Sensitise youth about the adverse effects of substance abuse}

Findings indicate that substantial proportions of young men reported the consumption of tobacco and alcohol. Efforts are needed to sensitise young men about the adverse effects of substance abuse.

\section{Directions for future research}

Findings presented in this report provide a broad picture of youth in India. At the same time, findings have raised a number of issues that require further investigation, particularly with regard to the determinants and consequences of youth behaviours and practices during the transition to adulthood. While the Youth Study is indeed a rich source of data that will enable investigators to fill many of the information gaps identified, there are several gaps in knowledge that will require additional research.

Youth Study findings highlight the need for further research in terms of formative research that explores in greater depth factors impeding successful transitions to adulthood, including enrolment in school and school completion, entry into the labour force, initiation of sexual activity, and marriage and parenthood. Research is also needed that explores the role of peers and the media, socialisation practices, young people's access to information and services, and the ways in which these factors contribute to or impede young people's ability to make successful transitions. 
A better understanding is required moreover of the factors underlying young people's agency and the expression of unequal and equal gender role attitudes. Also required are efforts to refine measures of agency as applicable to young men and women. A general research recommendation is the urgent need for prospective or panel study designs that follow a cohort of adolescents at regular intervals up to age 24. Prospective study designs would enable researchers to take a life course approach, identify, with compelling data, the factors responsible for healthy transitions to adulthood and point to the ways in which the situation and experiences of youth in adolescence influence their life course at later ages.

Operations research is also needed. While a number of interventions have been initiated in the country intended to address the needs of youth-for example, addressing the needs of married girls, changing the norms of masculinity and femininity, encouraging education for girls, developing market-based vocational skills and providing family life and sex education-few of these have been rigorously evaluated. Urgently needed, therefore, are carefully designed and rigorously tested intervention models that not only pay attention to the content and delivery of the intervention but also measure effectiveness and acceptability-in short, that will enable a shift from the implementation of promising to best practices in addressing young people's needs. In order to inform the field, multiple inputs are required. Ultimately, research is needed that monitors the scaling up of successful interventions in terms of their impact on young people's lives.

In brief, the Youth Study has documented, for the first time, the multi-faceted situation of youth in India. The study alerts us to the many challenges confronting youth and their ability to make a successful transition to adulthood. It emphasises the heterogeneity of youth, not only in terms of their situation but also with regard to their stated needs and preferred mechanisms to address these needs. Programmes must recognise the heterogeneity of young people and interventions and delivery mechanisms should be appropriately tailored to meet their needs. Evidence presented here provides not only a blue-print for the programming needs of youth in the country but also a base-line by which to measure the impact of programmes intended to address youth needs. 


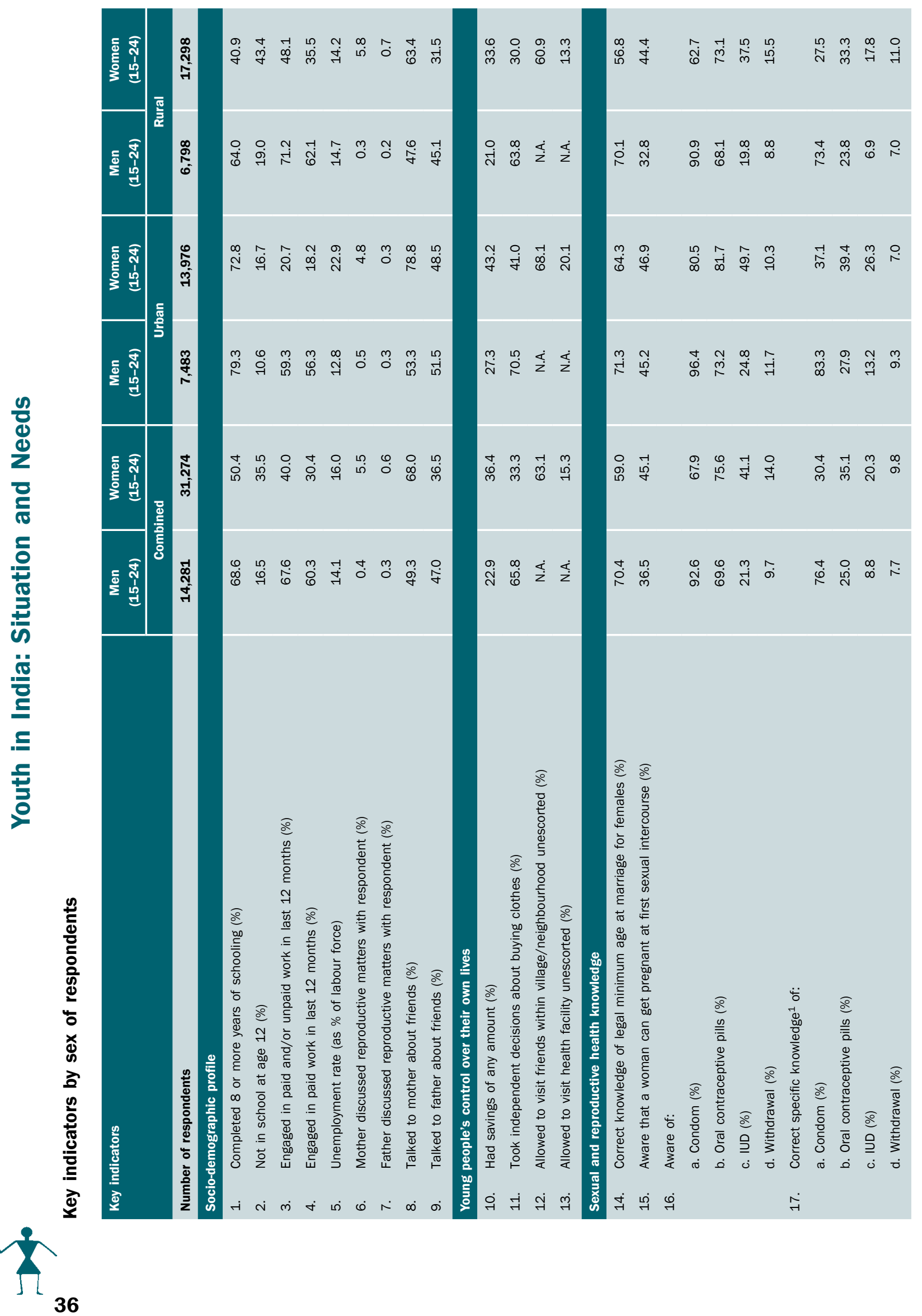




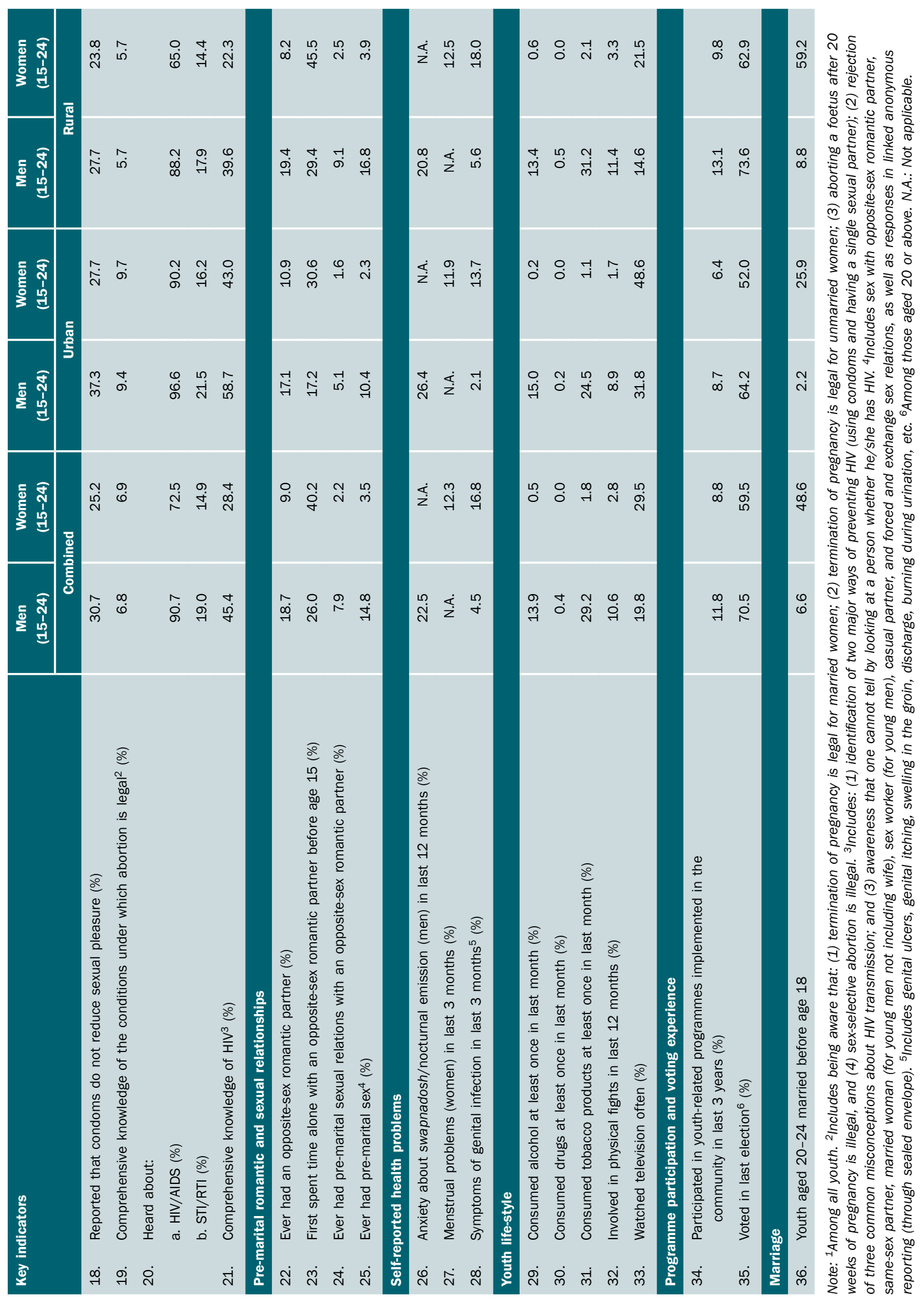




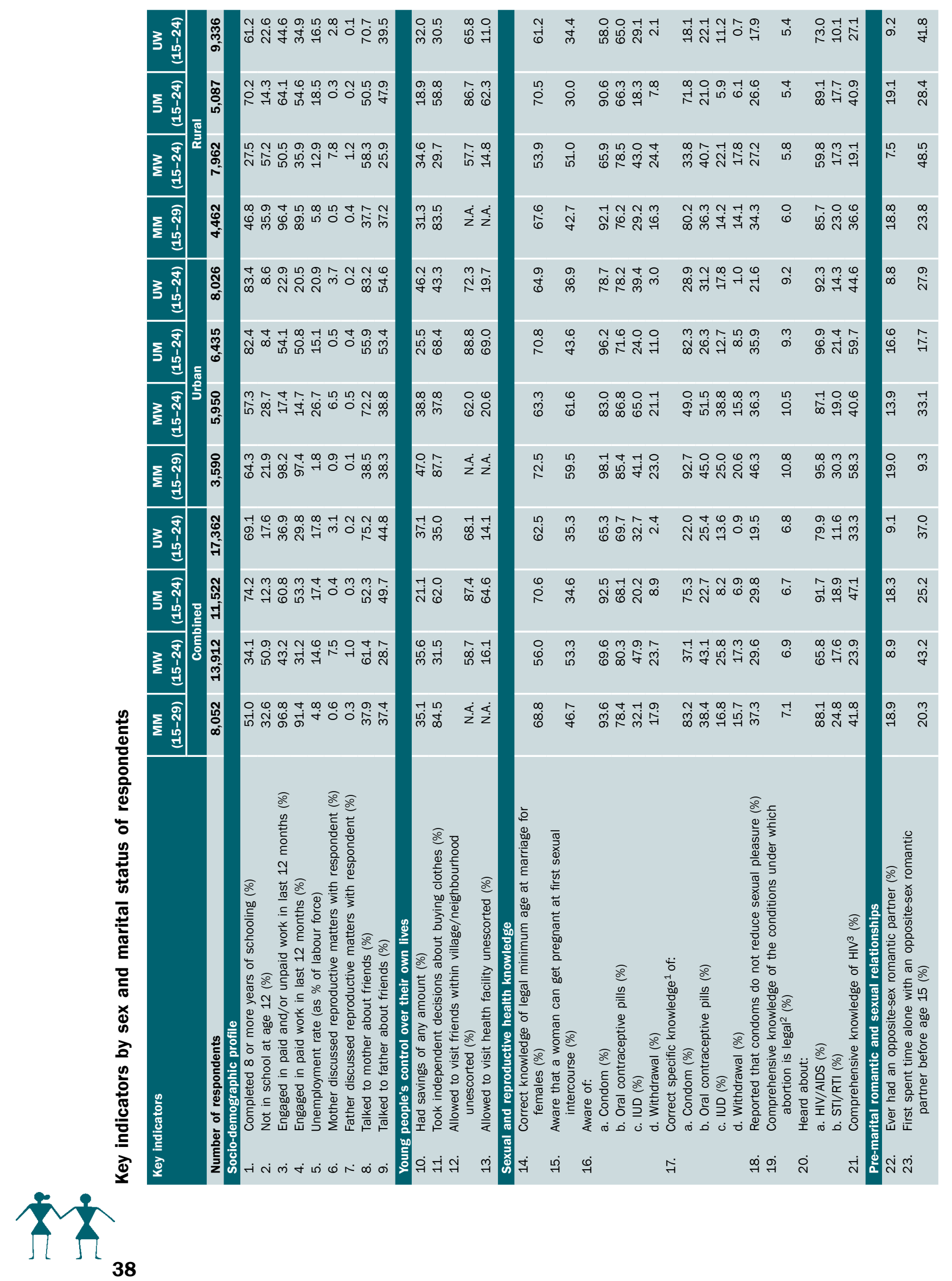




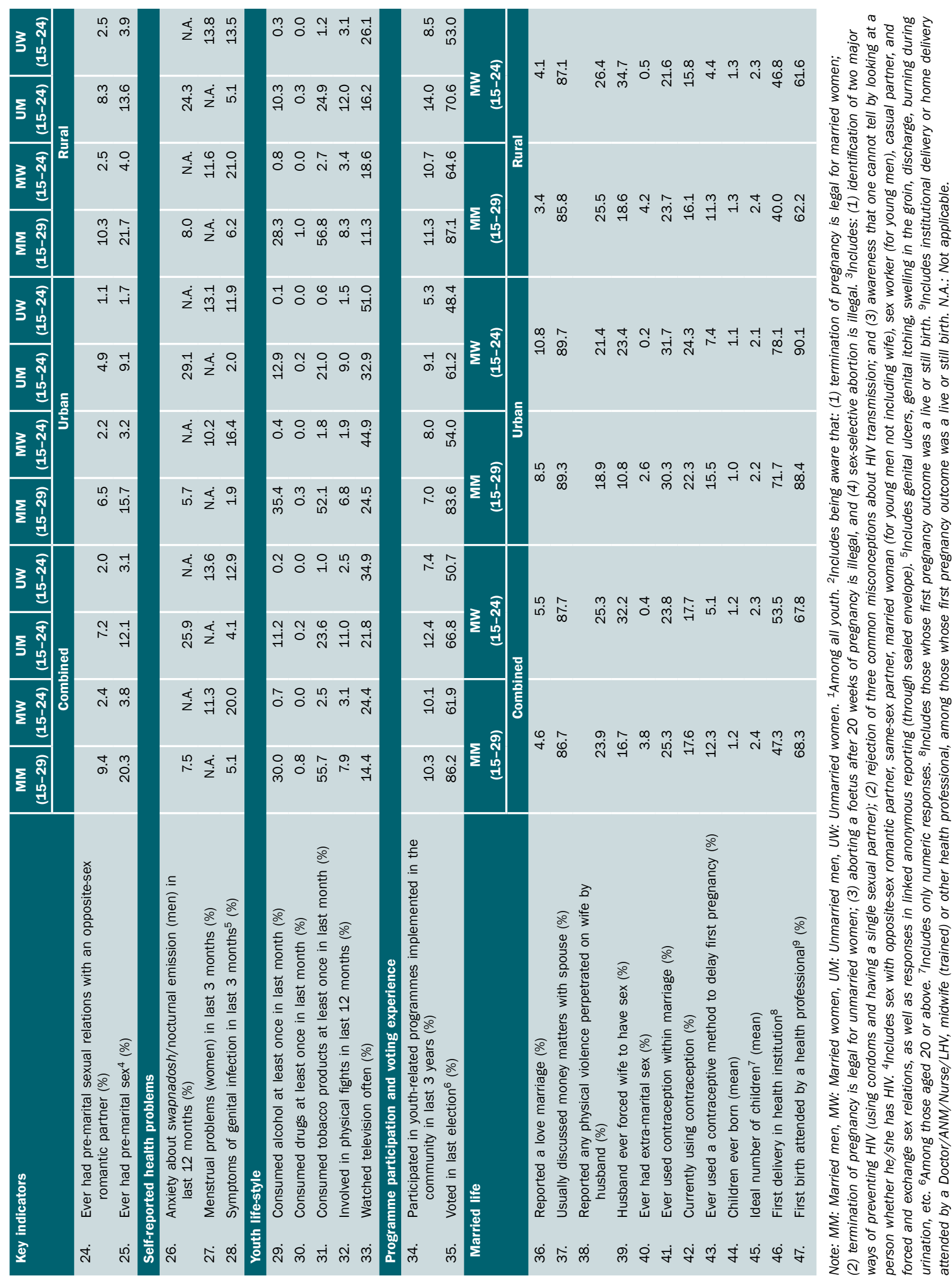




\section{Notes}




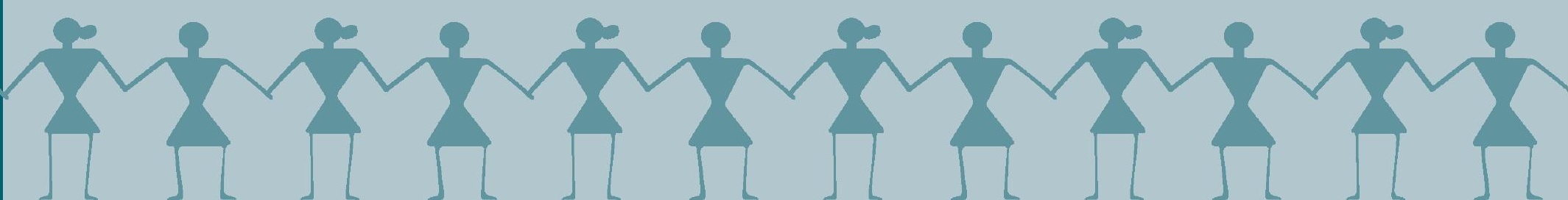


